Article

\title{
Simulation of the Potential Impacts of Projected Climate Change on Streamflow in the Vakhsh River Basin in Central Asia under CMIP5 RCP Scenarios
}

\author{
Aminjon Gulakhmadov ${ }^{1,2,3,4} \mathbb{C}^{(}, X_{i}$ Chen ${ }^{1,2, *}$, Nekruz Gulahmadov ${ }^{1,3,5}$, Tie Liu ${ }^{1} \mathbb{D}$, \\ Muhammad Naveed Anjum ${ }^{6}$ and Muhammad Rizwan ${ }^{5,7}$ \\ 1 State Key Laboratory of Desert and Oasis Ecology, Xinjiang Institute of Ecology and Geography, \\ Chinese Academy of Sciences, Urumqi 830011, China; aminjon@ms.xjb.ac.cn (A.G.); \\ nekruz.abdujabborovich@mails.ucas.ac.cn (N.G.); liutie@ms.xjb.ac.cn (T.L.) \\ 2 Research Center for Ecology and Environment of Central Asia, Chinese Academy of Sciences, \\ Urumqi 830011, China \\ 3 Institute of Water Problems, Hydropower and Ecology of the Academy of Sciences of the Republic of \\ Tajikistan, Dushanbe 734042, Tajikistan \\ 4 Ministry of Energy and Water Resources of the Republic of Tajikistan, Dushanbe 734064, Tajikistan \\ 5 University of Chinese Academy of Sciences, Beijing 100049, China; rizwan514@lzb.ac.cn \\ 6 Department of Land and Water Conservation Engineering, Faculty of Agricultural Engineering and \\ Technology, Pir Mehr Ali Shah Arid Agriculture University Rawalpindi, Rawalpindi 46000, Pakistan; \\ naveedwre@yahoo.com \\ 7 Key Laboratory of Remote Sensing and Geospatial Science, Northwest Institute of Eco-Environment and \\ Resources, Chinese Academy of Sciences, Lanzhou 730000, China \\ * Correspondence: chenxi@ms.xjb.ac.cn; Tel.: +86-136-0992-3012
}

Received: 1 April 2020; Accepted: 15 May 2020; Published: 17 May 2020

check for updates

\begin{abstract}
Millions of people in Uzbekistan, Turkmenistan, Tajikistan, and Kyrgyzstan are dependent on the freshwater supply of the Vakhsh River system. Sustainable management of the water resources of the Vakhsh River Basin (VRB) requires comprehensive assessment regarding future climate change and its implications for streamflow. In this study, we assessed the potential impacts of projected climate change scenarios on the streamflow in the VRB for two future periods (2022-2060 and 2061-2099). The probable changes in the regional climate system were assessed using the outputs of five global climate models (GCMs) under two representative concentration pathways (RCPs), RCP4.5 and RCP8.5. The probable streamflow was simulated using a semi-distributed hydrological model, namely the Soil and Water Assessment Tool (SWAT). Evidence of a significant increase in the annual average temperature by the end of the 21st century was found, ranging from 2.25 to $4.40^{\circ} \mathrm{C}$ under $\mathrm{RCP} 4.5$ and from 4.40 to $6.60^{\circ} \mathrm{C}$ under RCP8.5. The results of three GCMs indicated a decreasing tendency of annual average precipitation (from $-1.7 \%$ to $-16.0 \%$ under RCP 4.5 and from $-3.4 \%$ to $-29.8 \%$ under RCP8.5). Under RCP8.5, two GCMs indicated an increase (from $2.3 \%$ to $5.3 \%$ ) in the average annual precipitation by the end of 2099. The simulated results of the hydrological model reported an increasing tendency of average annual streamflow, from $17.5 \%$ to $52.3 \%$ under both RCPs, by the end of 2099. A shift in the peak flow month was also found, i.e., from July to June, under both RCPs. It is expected that in the future, median and high flows might increase, whereas low flow might decrease by the end of 2099. It is concluded that the future seasonal streamflow in the VRB are highly uncertain due to the probable alterations in temperature and precipitation. The findings of the present study could be useful for understanding the future hydrological behavior of the Vakhsh River, for the planning of sustainable regional irrigation systems in the downstream countries, i.e., Uzbekistan and Turkmenistan, and for the construction of hydropower plants in the upstream countries.
\end{abstract}

Keywords: climate change; hydrological model; streamflow; global climate models; Vakhsh River Basin 


\section{Introduction}

Water resources are essential for the existence of life on this planet. Sustainable access to these resources is necessary for our livelihood, agriculture, hydropower generation, economic growth, and ecosystems [1]. It is quite well documented that climate change is altering the distribution of freshwater resources, and is also influencing the eco-hydrological processes in different river systems of the world [2-4].

In Central Asia, desiccation of the Aral Sea from the 1960s to the late 1980s and shrinking of glaciers in the mountains of Pamir-Alay and Tian Shan are clear indications of climate change in this region. The Amu Darya River drains into the Aral Sea [5]; the Vakhsh River, which was the focus of this study, is the second largest headwater tributary of the Amu Darya River, originating in the high mountains of Pamir-Alay, and is among the most meltwater-dependent river systems in Central Asia [6]. The total annual flow of the Vakhsh River is $20.22 \mathrm{~km}^{3} / y e a r$, and the area of irrigated land in this river system is about 172.2 thousand hectares [7]. The Vakhsh River is also a major source for the generation of green energy in Central Asia, with the Nurek Reservoir being the largest one in this region (water storage volume of $10.5 \mathrm{~km}^{3}$ ).

The most threatening consequence of climate variation in mountainous regions is the rapid melting of snow/glaciers. Global warming is causing the premature melting of snow/glaciers in such regions and is also altering the patterns of precipitation, which will eventually influence the seasonality of the river flows [8-11]. Deng et al. [12] reported that the temperature lapse rate (in the spring and fall) and the precipitation (in the summer) are major factors influencing the discharge in the Kaidu River Basin in the mountainous region of Central Asia. Several previous hydroclimatic investigations in the South and Central Asian countries have observed an increasing tendency in river flows. The increasing tendencies of flows were mostly associated with the accelerated melting of glaciers [13]. For instance, Mahmood et al. [14] predicted a 15\% increase in the future average annual flow of the Jhelum River, which is located in the western Himalayan mountain system. Garee et al. [15] projected that the future average annual flow of the Hunza River, in the Karakoram range, might increase up to $10 \%$. Conversely, the annual flows of Brahmaputra River, one of the major rivers in Asia, are expected to decrease in the future [16]. White et al. [17] projected that the Amu Darya River flow, in Central Asia, is expected to decrease by between $10 \%$ and $20 \%$. Kayumov et al. [18] studied the impacts of climate alteration on the glacier covers in Tajikistan, which is situated in Central Asia, and reported a decrease of the glaciated area of the country from $6.0 \%$ in the middle of the past century to about $4.8 \%$ in 2014 . Although past trends of the streamflow of the largest river of Tajikistan (the Vakhsh River) under the context of regional climate change were documented by Kayumov et al. [18], clear manifestations of future climate change and its subsequent impacts on the streamflow in the basin remain unknown.

In the Tian Shan, Pamir, North Karakoram, Himalayan, and Tibetan Plateau mountainous system, in the middle and at the end of the 21st century, continuous warming was projected on annual and seasonal scales [19-22]. In Central Asia, warming (up to $7.0^{\circ} \mathrm{C}$ according to Mannig et al. [23] and up to $6.5^{\circ} \mathrm{C}$ according to Reyer et al. [24]) is projected until the end of this century. Bollasina et al. [25] reported an increasing trend in the concentration of aerosols in the atmosphere of Asia. In addition, Xin et al. [26] reported that the increasing concentration of atmospheric aerosols could cause a warm atmosphere in South and Central Asia.

The trends in precipitation in Asia are not consistent. In Central Asia, a persistent decrease in the annual precipitation was found at the end of the 20th century [27]. Unger-Shayesteh et al. [28] also reported a decreasing trend of future precipitation in eastern Pamir. Conversely, Meng et al. [29] indicated a rising trend of precipitation in some regions of Central Asia for the 21st century, for instance in the Tian Shan mountains. Malsy et al. [30] pointed out that over the Central Asian region, mean and maximum annual precipitation, based on the different datasets, will vary by $13 \%$ and up to $42 \%$, 
respectively. Similarly, the study of future precipitation characteristics in river basins (Yellow and Xin Rivers) in China [31,32], in the Middle East [33], and in the westerly-dominated region of South Asia indicated a decreasing trend in summer precipitation [34]. However, an increasing trend of winter precipitation was reported by Luo et al. [35] for the Heihe River Basin. Babur et al. [36] projected possible annual variations in precipitation in the western part of the Himalayas and found a significant increase in precipitation ( $43 \%$ under representative concentration pathway (RCP) 4.5 and $51 \%$ under RCP8.5). Omani et al. [13] projected changes in winter precipitation in the Pamir-Alay mountain range in Central Asia for the 2070-2099 period relative to the baseline (1979-2008) period for the 14 GCMs under RCP4.5 (from $-4.48 \%$ to $35.91 \%$ ) and RCP8.5 (from $-8.62 \%$ to $61.29 \%$ ). These contradictions in previous findings suggest that the ability to predict the increasing or decreasing tendency of winter precipitation may vary from model to model.

Hydrological models help to understand and investigate the dynamic behavior of river flows. Globally, many different hydrological models in different regions and at different scales, for instance, lumped, semi-distributed, and distributed, have been used to study the impacts of climate change on hydrological systems [37-50]. These hydrological models can predict hydrological variables and components of interest, particularly when the overall hydrological response of the watershed is of interest in the future. The Soil and Water Assessment Tool (SWAT) has been extensively used in different regions to analyze many hydrological problems, including the assessment of potential water flow variations in future climate scenarios [51-54].

The main scientific objectives of this study were as follows: (1) To simulate the streamflow of a mountainous catchment with minimum parameter uncertainty and high confidence in prediction using a semi-distributed hydrological model (SWAT); (2) to evaluate the changes in median extreme (low and high) flows, as well as the temporal shifts in peak flows; and (3) to assess the likely impact of climate variation on the monthly, seasonal, and interannual flows and snowmelt of the Vakhsh River Basin (VRB) in a multimodal experiment using the results of five global climate models (GCMs).

Section 2 presents the materials and datasets used in this investigation. Section 3 describes the hydrological model, its calibration and validation, the uncertainty of the parameters, and the future scenarios. Section 4 presents the results and discussion. Finally, the conclusions are summarized in Section 5 . The results of this study could be helpful for researchers and policy-makers alike.

\section{Materials and Methods}

\subsection{Study Area}

The Vakhsh River Basin, the northeast tributary of the Amu Darya River, is located in Central Asia and flows from north-central Kyrgyzstan to the southwest of Tajikistan. The basin is situated between $37.10^{\circ}$ and $39.74^{\circ} \mathrm{N}$ and $68.31^{\circ}$ and $73.70^{\circ} \mathrm{E}$, and has a total length of $524 \mathrm{~km}$ with a drainage area of about $39,008 \mathrm{~km}^{2}$. The main tributaries of this river are Muksu and Obihingou. Elevation in the basin ranges from 302 to $7050 \mathrm{~m}$ above sea level (Figure 1). The climate of the basin is continental under the domination of the westerlies, with very high local contrasts because of the orographic conditions. The temperature decreases with the increase in elevation, while precipitation has different patterns at different altitudes and aspects. The respective values of the precipitation and average maximum/minimum temperature over the Vakhsh River Basin from 2000 to 2013 were $120 \mathrm{~mm}, 3.9^{\circ} \mathrm{C}$, $-3.4{ }^{\circ} \mathrm{C}$ in winter (December-February); $160 \mathrm{~mm}, 17.6^{\circ} \mathrm{C}, 7.3^{\circ} \mathrm{C}$ in spring (March-May); $27.4 \mathrm{~mm}$, $29.4^{\circ} \mathrm{C}, 16.1^{\circ} \mathrm{C}$ in summer (June-August); and $32 \mathrm{~mm}, 19^{\circ} \mathrm{C}, 7.2^{\circ} \mathrm{C}$ in the fall (September-November). The mean annual precipitation and maximum/minimum temperatures are $85 \mathrm{~mm}, 17.5^{\circ} \mathrm{C}$, and $6.8^{\circ} \mathrm{C}$, respectively (Figure 2). The snow/glacier meltwater in the Alay valley and in northern Pamir drains into the Vakhsh River. The average daily discharge at the Darband hydrological station was $673 \mathrm{~m}^{3} / \mathrm{s}$ for the 2000-2013 period, with a minimum value of $18 \mathrm{~m}^{3} / \mathrm{s}$ and a maximum value of $2704 \mathrm{~m}^{3} / \mathrm{s}$. The average annual flow is $660 \mathrm{~m}^{3} / \mathrm{s}$ (Figure 2). The Vakhsh River flows generally through a narrow valley, in places turning into impassable gorges $8-10 \mathrm{~m}$ wide, and in some places, it expands up to 
$1.5 \mathrm{~km}$. The Vakhsh River is considered one of the most important rivers in terms of power production potential in Tajikistan. Several large- and medium-sized hydropower plants (HPPs) have been installed on this river.

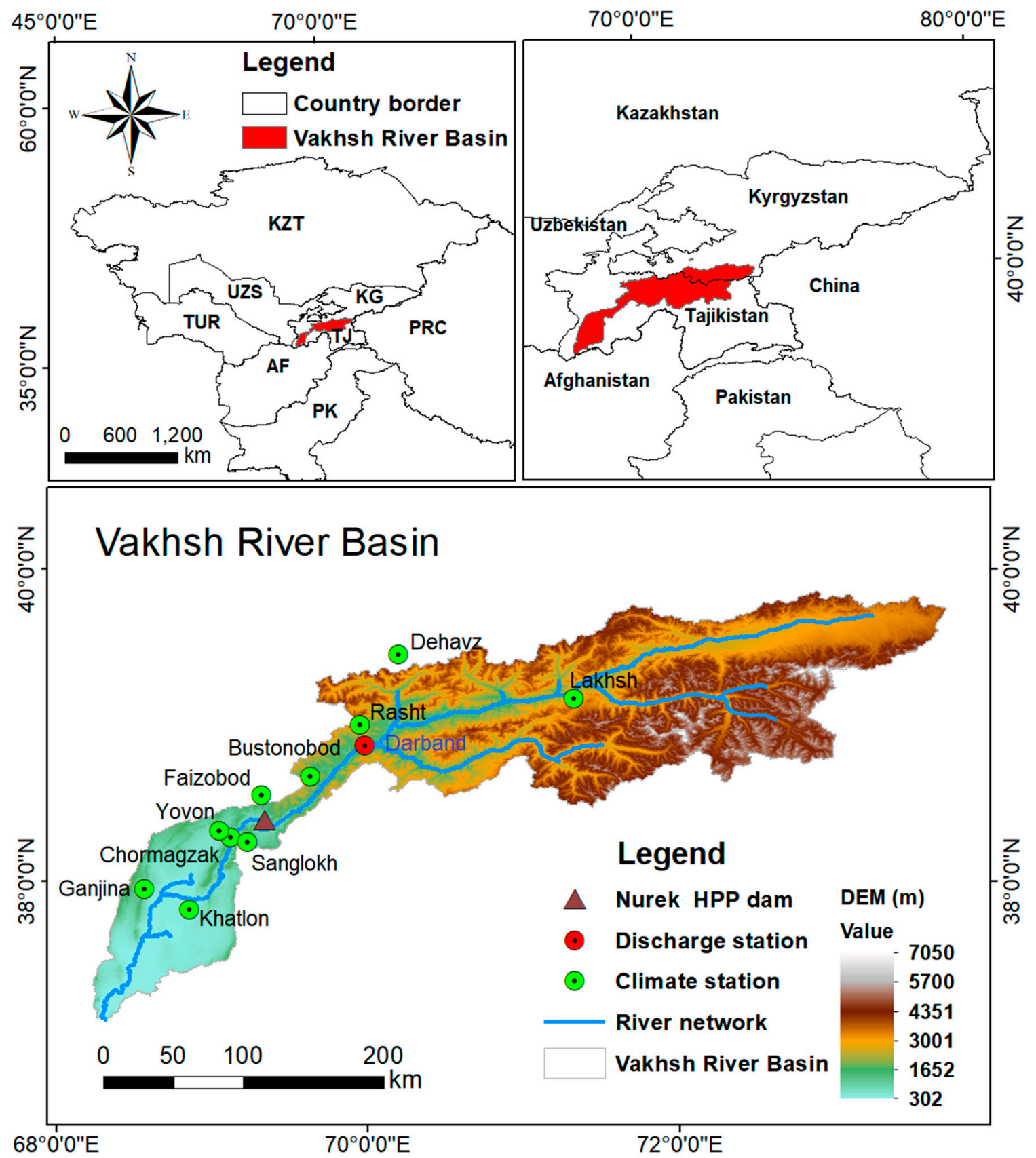

Figure 1. Location of the study area in Central Asia along with hydrological and climate stations. HPP: hydropower plant; DEM: digital elevation model. 

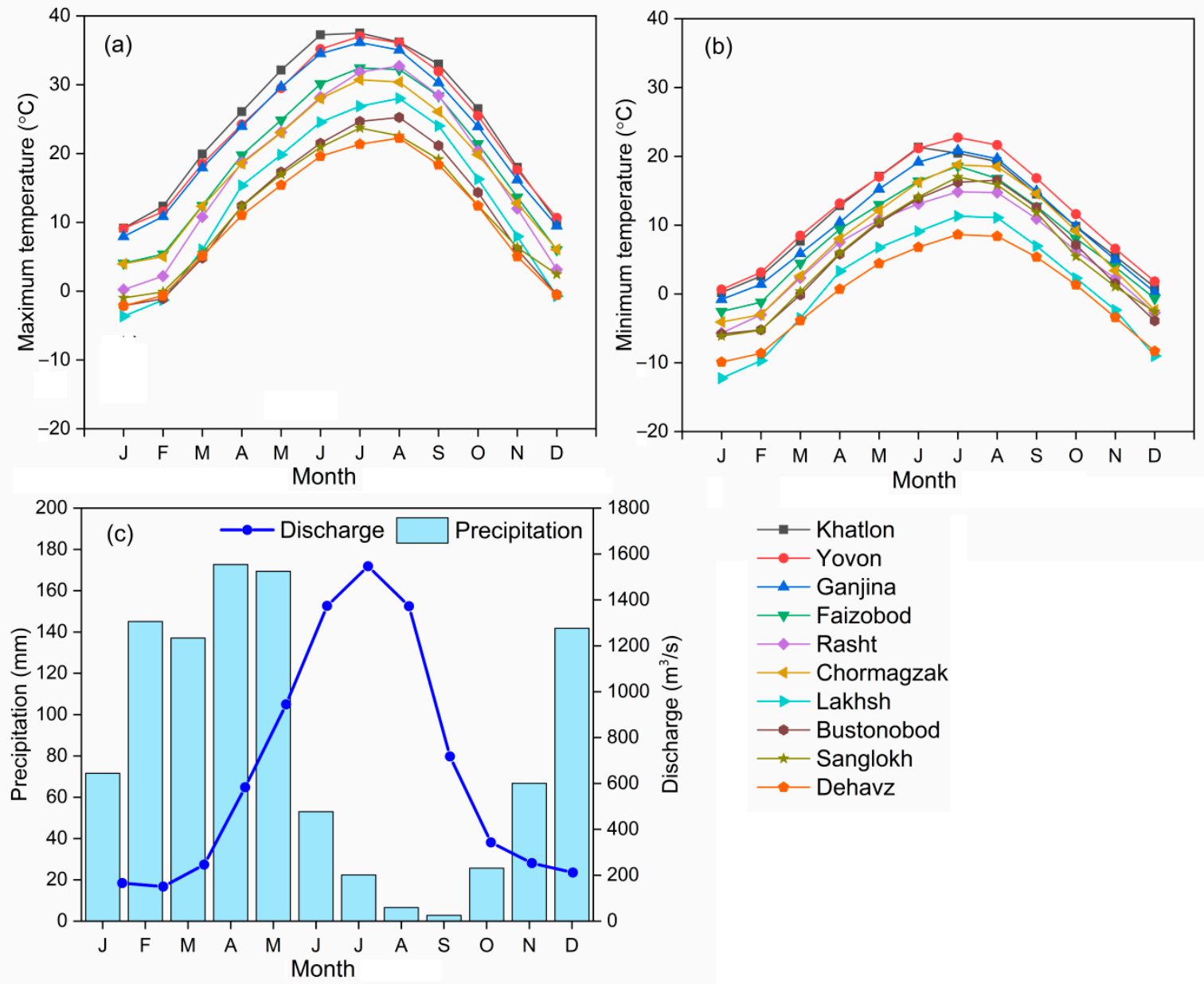

Figure 2. The mean monthly values of (a) the maximum temperature, (b) the minimum temperature, and (c) the streamflow and average monthly precipitation in the Vakhsh River Basin, Central Asia, from 2000 to 2013.

\subsection{Data}

Measured and GCM-Based Climate Datasets

The in situ gauge-based daily observations of the climatic parameters used in this study were obtained from the Agency of Hydrometeorology Committee on Environmental Protection under the Government of the Republic of Tajikistan. The daily observations of the river flow at the Darband hydrological station over the 2000-2013 period were obtained from the Ministry of Energy and Water Resources of the Republic of Tajikistan. The quality-ensured daily time series of maximum temperature (Tmax), minimum temperature (Tmin), average temperature (Tas), and precipitation (Pr) for ten meteorological stations (Khatlon, Yovon, Ganjina, Faizobod, Rasht, Chormagzak, Lakhsh, Bustonobod, Sanglokh, and Dehavz) were acquired for the 1966-2013 period. The gauge-based datasets were utilized for the calibration and validation of the SWAT model over the 2000-2013 period. The overall agreements between the gauge-based and GCM-based daily time series of the climatic parameters were assessed for the 1966-2004 period.

The simulated maximum/minimum temperature and precipitation data of the five GCMs under two RCPs (4.5 and 8.5) were downloaded from the www.2w2e.com website and downscaled using the Climate Change Toolkit [55] for the study area. Table 1 describes the outputs of the GCMs, which were based on the ISI-MIP (Inter-Sectoral Impact Model Intercomparison Project) [56], used in this study. The simulated results of Pr, Tmax, and Tmin of the five GCMs were extracted for the control period 
(1966-2004) and for two future time periods (2022-2060 and 2061-2099). GCM results were also obtained for medium $\left(4.5 \mathrm{~W} / \mathrm{m}^{2}\right)$ and high $\left(8.5 \mathrm{~W} / \mathrm{m}^{2}\right)$ concentration scenarios.

Table 1. Details of the general circulation models (GCMs) used for the projection of the precipitation and maximum/minimum temperature in the Vakhsh River Basin. The emission scenarios (RCPs) and the time periods considered in the calculation of the change factors and future climate change impacts on streamflow are also provided.

\begin{tabular}{|c|c|c|c|c|c|c|}
\hline Model & ISI-MIP Model & Institute & $\begin{array}{l}\text { Emission } \\
\text { Scenarios }\end{array}$ & Variable & $\begin{array}{c}\text { Historical } \\
\text { Period }\end{array}$ & $\begin{array}{l}\text { Future Time } \\
\text { Periods }\end{array}$ \\
\hline GCM1 & GFDL-ESM2M & $\begin{array}{c}\text { NOAA/Geophysical } \\
\text { Fluid Dynamics } \\
\text { Laboratory }\end{array}$ & $\begin{array}{l}\text { RCPs } 4.5 \\
\text { and } 8.5\end{array}$ & $\begin{array}{l}\text { Pr, Tmax, } \\
\text { Tmin }\end{array}$ & 1966-2004 & $\begin{array}{l}\text { 2022-2060, } \\
2061-2099\end{array}$ \\
\hline GCM2 & HadGEM2-ES & $\begin{array}{l}\text { Met Office Hadley } \\
\text { Center }\end{array}$ & $\begin{array}{l}\text { RCPs } 4.5 \\
\text { and } 8.5\end{array}$ & $\begin{array}{l}\text { Pr, Tmax, } \\
\text { Tmin }\end{array}$ & 1966-2004 & $\begin{array}{l}\text { 2022-2060, } \\
2061-2099\end{array}$ \\
\hline GCM3 & IPSL-CM5A-LR & $\begin{array}{l}\text { L'Institute } \\
\text { Pierre-Simon } \\
\text { Laplace }\end{array}$ & $\begin{array}{l}\text { RCPs } 4.5 \\
\text { and } 8.5\end{array}$ & $\begin{array}{l}\text { Pr, Tmax, } \\
\text { Tmin }\end{array}$ & 1966-2004 & $\begin{array}{l}2022-2060 \\
2061-2099\end{array}$ \\
\hline GCM4 & MIROC & $\begin{array}{l}\text { AORI, NIES and } \\
\text { JAMSTEC }\end{array}$ & $\begin{array}{l}\text { RCPs } 4.5 \\
\text { and } 8.5\end{array}$ & $\begin{array}{l}\text { Pr, Tmax, } \\
\text { Tmin }\end{array}$ & 1966-2004 & $\begin{array}{l}\text { 2022-2060, } \\
2061-2099\end{array}$ \\
\hline GCM5 & NoerESM1-M & $\begin{array}{c}\text { Norwegian Climate } \\
\text { Center }\end{array}$ & $\begin{array}{l}\text { RCPs } 4.5 \\
\text { and } 8.5\end{array}$ & $\begin{array}{l}\text { Pr, Tmax, } \\
\text { Tmin }\end{array}$ & 1966-2004 & $\begin{array}{l}2022-2060 \\
2061-2099\end{array}$ \\
\hline
\end{tabular}

ISI-MIP: Inter-Sectoral Impact Model Intercomparison Project; NOAA: National Oceanic and Atmospheric Administration; AORI: Atmosphere and Ocean Research Institute; NIES: National Institute for Environmental Studies; JAMSTEC: Japan Agency for Marine-Earth Science and Technology.

\subsection{The Digital Elevation Model (DEM), Land Cover, and Soil Data}

In this study, a digital elevation model (DEM) with a $90 \mathrm{~m}$ spatial resolution was obtained from the website of the Shuttle Radar Topographic Mission (SRTM) [57], which was utilized for the demarcation of the catchment boundary and the river network. The land use map of the study area at the $300 \times 300 \mathrm{~m}$ grid scale was acquired from the Envisat Medium-Resolution Imaging Spectrometer (MERIS) [58]. Different land cover types such as wetlands $(0.27 \%)$, water bodies $(0.92 \%)$, urban areas $(2.49 \%)$, forests $(3.35 \%)$, agricultural areas $(6.65 \%)$, bare land $(9.80 \%)$, snow and ice $(10.67 \%)$, bare rock gravel $(24.30 \%)$, and grasslands $(41.54 \%)$ were identified in the basin.

The soil map for the VRB was derived from version 1.2 of the Harmonized World Soil Database (HWSD), with a scale of 1:5,000,000. The HWSD is freely available on the website of the Food and Agriculture Organization (FAO) of the United Nations [59]. The soil layer obtained from the HWSD contained information on the chemical and physical properties of the soil, e.g., depth from the surface to the bottom of the soil, moist bulk density, clay content, silt content, and sand content. Therefore, a soil map was used directly in the hydrological model. Using the HWSD-based map, the silt, sand, and clay properties were computed on a percentage basis, which satisfied the model input data requirements, such as the saturated hydraulic conductivity and available water capacity. In this study, the prominent soil types were chromic cambisols $(40.01 \%)$, ferralic arenosols $(23.75 \%)$, calcic luvisols $(22.68 \%)$, chromic luvisols $(8.57 \%)$, haplic phaeozems (2.73\%), dystric regosols (1.59\%), and lithic leptosols $(0.67 \%)$.

\subsection{Soil and Water Assessment Tool (SWAT)}

The Soil and Water Assessment Tool, developed by the Agricultural Research Service of the United States Department of Agriculture, is a physically based semi-distributed hydrology model. The simulation in this model can be performed in daily and subdaily time steps [60,61]. A schematic illustration of the SWAT model is presented in Figure 3. It is capable of simulating the impacts of climate change and land management measures on water availability, as well as the sediment transport in small-to-large ungauged river basins on the basis of soil types, land uses, and management circumstances [62]. Initially, this hydrological model was developed to quantify the impact of land-use 
practices in large compound catchments. It is a flexible tool, and the model has been frequently applied in mountainous river basins [63-65]. It has been widely used for the assessment and adaptation of schemes to climate change, flood control, and hydropower management practices [66,67]. In the SWAT model, a catchment can be classified into different hydrological response units (HRUs) by overlaying soil characteristics, topography, land use, and management schemes. This model is able to calculate snowmelt proportions using a temperature index algorithm (TIA), and is a very efficient approach to analyzing the climate change impact on the streamflow in snow/glacier-dominated river basins. The SWAT model has the provision to divide each sub-basin into 10 elevation bands. The TIA approach was applied previously in the Yellow River basin [68], the Jhelum River Basin [36], and the Hunza River Basin [15] to simulate the streamflow in these mountainous watersheds. In this analysis, the TIA approach was utilized to estimate the snow/glacier meltwater. In the current research, each sub-basin in the Vakhsh River Basin was split into five elevation bands (EBs). The laps rate approach was used to estimate the precipitation, maximum temperature, and minimum temperature for each EB. The hydrological SWAT model is able to calculate evapotranspiration (ET) using the Penman-Monteith, Hargreaves, and Priestley-Taylor approaches, but we used the Hargreaves approach to evaluate the ET in the Vakhsh River Basin.
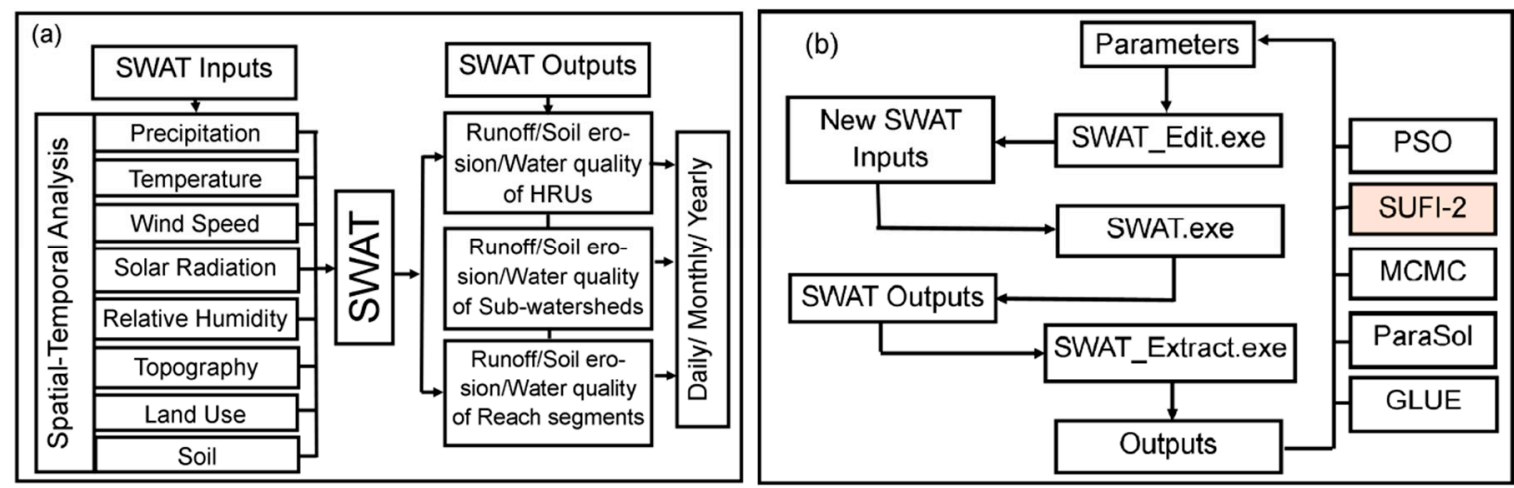

Figure 3. (a) Schematic overview of the Soil and Water Assessment Tool (SWAT) model; (b) the relationship between the Soil and Water Assessment Tool—Calibration and Uncertainty Procedures (SWAT_CUP) and its five optimization algorithms. HRU: hydrological response unit; SUFI-2, Sequential Uncertainty Fitting version 2; PSO: particle swarm optimization; MCMC: Markov chain Monte Carlo; GLUE: generalized likelihood uncertainty estimation.

For the current study, 19 sub-basins and 1048 HRUs in the Vakhsh River Basin were delineated using ArcSWAT 2012 (version 664). For model simulation, the daily measurement-based precipitation and maximum/minimum temperature data for a period of 14 years (2000-2013) were taken into consideration. The first three years (2000-2002) were used as the warm-up period. The daily and monthly simulated streamflow was calibrated for the 2003-2008 time period and was then validated for the 2009-2013 period for the hydrological model, based on the flow data measured at the Darband hydrological station.

\subsubsection{Sequential Uncertainty Fitting Version 2 (SUFI-2)}

The semi-automatic calibration and validation approach was used in this study by applying the Sequential Uncertainty Fitting version 2 (SUFI-2) algorithm in the Soil and Water Assessment Tool-Calibration and Uncertainty Procedures (SWAT-CUP) tool package [69]. In the calibration, SUFI-2 expresses the errors and uncertainties during the hydrological modeling to a certain degree, as well as the ignorance and lack of understanding of the processes in natural systems. There is a close relationship between calibration and uncertainty. According to Abbaspour [70], without uncertainty, the calibration of the model is meaningless and deceptive. Moreover, any analysis with the calibrated model must include the uncertainty in the result based on the parameter uncertainties. 


\subsubsection{Elevation Bands}

Taking into account the influence of the precipitation and temperature in mountainous regions, the division of the river basin into different elevation bands is regarded as a very important procedure. The SWAT model allows a basin to be divided into up to 10 elevation bands. In this study, the basin was divided into five elevation bands (EBs). Using the following mathematic equations, we adjusted the temperature and precipitation of each band.

$$
\begin{aligned}
& \mathrm{R}_{\mathrm{band}}=\mathrm{R}_{\text {day }}+\left(\mathrm{EL}_{\mathrm{band}}-\mathrm{EL}_{\mathrm{c.s}}\right) \times \frac{\mathrm{plaps}}{\text { days }_{\mathrm{pcp}, \mathrm{yr}} \times 1000}, \mathrm{R}_{\text {day }}>0.01, \\
& \mathrm{~T}_{\text {max }, \text { band }}=\mathrm{T}_{\max }+\left(\mathrm{EL}_{\mathrm{band}}-\mathrm{EL}_{\mathrm{c.s}}\right) \times \frac{\text { tlaps }}{1000}, \\
& \mathrm{~T}_{\text {min,band }}=\mathrm{T}_{\min }+\left(\mathrm{EL}_{\text {band }}-\mathrm{EL}_{\mathrm{c.s}}\right) \times \frac{\text { tlaps }}{1000}, \\
& \mathrm{~T}_{\text {mean,band }}=\mathrm{T}_{\text {mean }}+\left(\mathrm{EL}_{\text {band }}-\mathrm{EL}_{\mathrm{c.s}}\right) \times \frac{\text { tlaps }}{1000},
\end{aligned}
$$

where $R_{\text {band }}$ indicates the precipitation in an $\mathrm{EB}(\mathrm{mm}) ; \mathrm{R}_{\text {day }}$ indicates the precipitation measured at the observed climate point (mm); $\mathrm{EL}_{\text {band }}$ is the average elevation in the $\mathrm{EB}(\mathrm{m}) ; \mathrm{EL}_{\mathrm{c.s}}$ is the elevation at the climate point $(\mathrm{m})$; plaps indicates the precipitation lapse rate $(\mathrm{mm} / \mathrm{km})$; days $\mathrm{pcp}_{\mathrm{yr}}$ shows the mean annual number of precipitation days in the sub-basin; $T_{\max }$ band is the EB's maximum daily temperature (C); $T_{\min , \text { band }}$ is the EB's minimum daily temperature $(C) ; T_{\text {mean,band shows the } E B^{\prime} s \text { mean }}$ daily temperature $(C) ; T_{\max }$ is the maximum daily temperature measured at the climate station $(C)$; $\mathrm{T}_{\min }$ is the minimum daily temperature measured at the climate station $(C) ; \mathrm{T}_{\text {mean }}$ is the mean daily temperature measured at the climate station $(C)$; tlaps shows the lapse rate of temperature $(\mathrm{C} / \mathrm{km})$; and 1000 is the conversion factor from meters to kilometers.

\subsection{Calibration, Validation, and Sensitivity Analysis}

In this study, the SWAT-CUP tool package was applied to calibrate the model parameters. This tool package is capable of offering two different sensitivity analyses, namely global and one-at-a-time sensitivity analyses. The one-at-a-time sensitivity analysis requires a separate sensitivity analysis of each parameter. In many cases, the sensitivity of one parameter depends on the other parameters. To facilitate work in a stationary computer and to avoid needing a more complicated sensitivity analysis to fix the range of values, in this calibration procedure, the global sensitivity analysis approach was used, which allowed us to analyze the sensitivity of all parameters in combination and to determine the key parameters in each hydrological sub-basin. Among the selected sensitive parameters, 14 were characteristically related to streamflow. By using the SUFI-2 model, the parameter sensitivity was evaluated based on the multiple regression system presented by Yang et al. [71] to estimate the effect of the selected value of the parameter $\left(b_{i}\right)$ in the objective function $(\mathrm{g})$. The following equation was used to calculate the parameter sensitivities.

$$
\mathrm{g}=\propto+\sum_{\mathrm{i}=1}^{\mathrm{m}} \beta_{\mathrm{i}} \mathrm{b}_{\mathrm{i}}
$$

The average changes of the parameter selected during the sensitivity analysis in the objective function could be computed using the above formula.

\section{Assessment of the Hydrological Model's Performance}

To evaluate the performance of the SWAT model, five indices were used: the coefficient of determination $\left(\mathrm{R}^{2}\right)$, the Nash-Sutcliffe efficiency (NSE) [72], the percent bias (PBIAS), the root-mean-square error standard deviation ratio (RSR), and the mean square error method (MSE). If the NSE and $\mathrm{R}^{2}$ are both $>0.5$, then the SWAT model presents satisfactory outcomes; the range 
of $R^{2}$ is -1 to 1 and that for NSE is 0 to 1 . Less error and better performance of the simulated results are indicated by higher values of NSE and $R^{2}$. The range of acceptable PBIAS values is $-15<$ PBIAS $<+15$; the best value is zero, and negative and positive values indicate model overestimation and underestimation, respectively. The RSR values range from zero to high positive values, and lower values of RSR show better model application [73]. The mathematical delimitations of the PBIAS, RSR, NSE, and $\mathrm{R}^{2}$ objective functions are expressed below.

$$
\begin{aligned}
& \text { PBIAS }=\frac{\sum_{\mathrm{i}=1}^{\mathrm{n}}\left(\mathrm{Q}_{\mathrm{i}}^{\text {obs }}-\mathrm{Q}_{\mathrm{i}}^{\text {sim }}\right) \times 100}{\sum_{\mathrm{i}=1}^{\mathrm{n}}\left(\mathrm{Q}_{\mathrm{i}}^{\mathrm{obs}}\right)}, \\
& \text { RMSE }=\sqrt{\frac{\sum_{i=1}^{\mathrm{n}}\left(\mathrm{Q}_{\mathrm{i}}^{\text {sim }}-\mathrm{Q}_{\mathrm{i}}^{\text {obs }}\right)^{2}}{\mathrm{n}}}, \\
& \operatorname{RSR}=\frac{\sqrt{\sum_{\mathrm{i}=1}^{\mathrm{n}}\left(\mathrm{Q}_{\mathrm{i}}^{\text {obs }}-\mathrm{Q}_{\mathrm{i}}^{\text {sim }}\right)^{2}}}{\sqrt{\sum_{\mathrm{i}=1}^{\mathrm{n}}\left(\mathrm{Q}_{\mathrm{i}}^{\text {obs }}-\overline{\mathrm{Q}^{\text {obs }}}\right)^{2}}} \\
& \mathrm{NSE}=1-\frac{\sum_{\mathrm{i}=1}^{\mathrm{n}}\left(\mathrm{Q}_{\mathrm{i}}^{\text {sim }}-\mathrm{Q}_{\mathrm{i}}^{\text {obs }}\right)^{2}}{\sum_{\mathrm{i}=1}^{\mathrm{n}}\left(\mathrm{Q}_{\mathrm{i}}^{\mathrm{obs}}-\overline{\mathrm{Q}^{\mathrm{obs}}}\right)^{2}}, \\
& \mathrm{R}^{2}=\frac{\left[\sum_{\mathrm{i}=1}^{\mathrm{n}}\left(\mathrm{Q}_{\mathrm{i}}^{\mathrm{obs}}-\overline{\mathrm{Q}^{\mathrm{obs}}}\right)\left(\mathrm{Q}_{\mathrm{i}}^{\mathrm{sim}}-\overline{\mathrm{Q}^{\mathrm{sim}}}\right)\right]^{2}}{\sum_{\mathrm{i}=1}^{\mathrm{n}}\left(\mathrm{Q}_{\mathrm{i}}^{\mathrm{obs}}-\overline{\mathrm{Q}^{\mathrm{obs}}}\right)^{2} \sum_{\mathrm{i}=1}^{\mathrm{n}}\left(\mathrm{Q}_{\mathrm{i}}^{\mathrm{sim}}-\overline{\mathrm{Q}^{\mathrm{sim}}}\right)^{2}}
\end{aligned}
$$

where $\mathrm{n}$ shows the entire number of sample pairs, $\mathrm{Q}_{\mathrm{i}}^{\text {obs }}$ indicates the measured discharge station variable, $\overline{Q^{\text {obs }}}$ indicates the average of the measured discharge station variables, $Q_{i}^{\text {sim }}$ shows the simulated discharge variable, $\overline{Q^{\text {sim }}}$ is the average of the simulated discharge variables, and $i$ is the ith measured station or simulated data.

\subsection{Additive and Multiplicative Methods of Change Factors}

The five sets of GCM data (1966-2099) at the spatial resolution of $0.5^{\circ}$ were downloaded from the study domain www.2w2e.com and were downscaled using the Climate Change Toolkit (CCT); a detailed description of the CCT software is given in the supplementary material and can be downloaded along with the program from www.2w2e.com. The datasets from www.2w2e.com and CCT software have been used by many researchers, including Ashraf Vaghefi et al. [55] in America and Touseaf et al. [74] over Xijiang River Basin in China. In this study, under the two scenarios (RCPs 4.5 and RCP8.5), the meteorological variables, namely precipitation and maximum/minimum temperatures, were analyzed for two future time periods (2022-2060 and 2061-2099) with reference to the baseline condition, i.e., the 1966-2004 historical period. In order to obtain the future values of the current grid, the current variation was then coupled to the measured station variables. The mathematical formulation of additive change factor method (CFM) was used to evaluate the absolute change in the temperature of the GCM $[75,76]$. The observed values were multiplied by the change factor after calculating the arithmetic difference between the current and future GCM values. Characteristically, this method used for the precipitation of the GCM produces a reasonable evaluation of the value of a variable with respect to the relative change [75-77]. Figure 4 shows a schematic illustration of the method used for the evaluation of future scenarios using the multiplicative and additive change factors. The calculation of change factors may be applied to a single grid point of a GCM or to the average of several grid points. Equations (11) and (12) were used to estimate the monthly average 
values for GCM-based precipitation and maximum/minimum temperatures for the future scenarios and the baseline condition.

$$
\begin{gathered}
\overline{\mathrm{GCMb}}=\sum_{\mathrm{i}=1}^{\mathrm{Nb}} \mathrm{GCMb}_{\mathrm{i}} / \mathrm{Nb}, \\
\overline{\mathrm{GCMf}}=\sum_{\mathrm{i}=1}^{\mathrm{Nf}} \mathrm{GCMf}_{\mathrm{i}} / \mathrm{Nf},
\end{gathered}
$$

The $\mathrm{GCMb}_{\mathrm{i}}$ and $\mathrm{GCMf}_{\mathrm{i}}$ values show the GCM's future climate scenario and the GCM's baseline condition, $\overline{\mathrm{GCMb}}$ and $\overline{\mathrm{GCMf}}$ are the average values, and $\mathrm{Nb}$ and $\mathrm{Nf}$ present the number of variables at the temporal scale of the GCM's future climate scenario and the GCM's baseline condition, respectively.
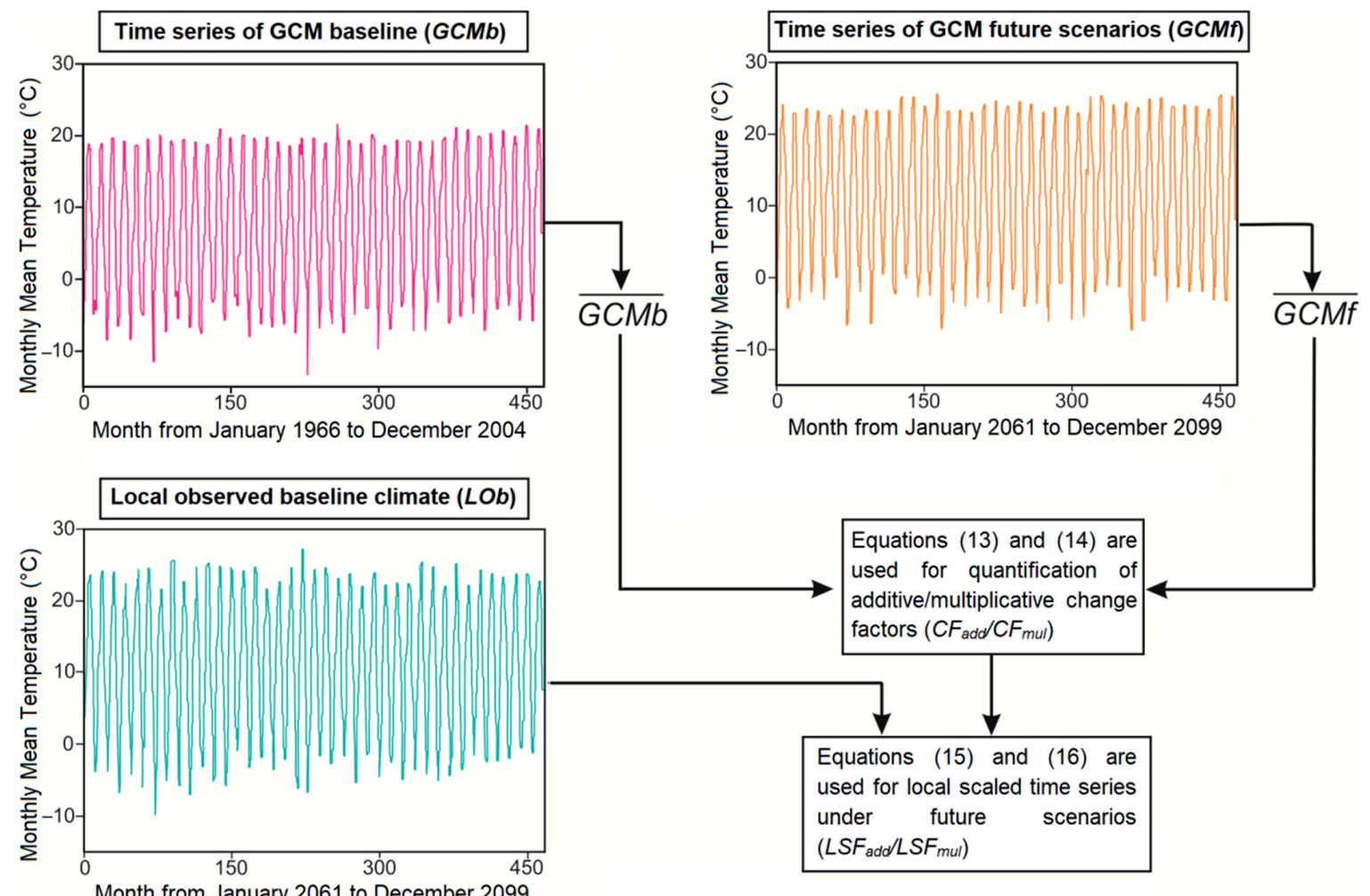

Figure 4. Method to evaluate future scenarios by applying the multiplicative and additive change factors.

To calculate the additive change factor $\left(\mathrm{CF}_{\text {add }}\right)$ for the maximum/minimum temperatures and the multiplicative change factor $\left(\mathrm{CF}_{\mathrm{mul}}\right)$ for the precipitation, Equations (13) and (14) were used.

$$
\begin{aligned}
\mathrm{CF}_{\text {add }} & =\overline{\mathrm{GCMf}}-\overline{\mathrm{GCMb}}, \\
\mathrm{CF}_{\text {mul }} & =\overline{\mathrm{GCMf}} / \overline{\mathrm{GCMb}},
\end{aligned}
$$

The new locally scaled future additive $\left(\mathrm{LSf}_{\mathrm{add}, \mathrm{i}}\right)$ and the multiplicative $\left(\mathrm{LSf}_{\mathrm{mul}, \mathrm{i}}\right)$ change factors from Equations (15) and (16) were obtained based on the values $\left(\mathrm{CF}_{\mathrm{add}}\right)$ and $\left(\mathrm{CF}_{\mathrm{mul}}\right)$ [78].

$$
\begin{aligned}
& \mathrm{LSf}_{\text {add }, \mathrm{i}}=\mathrm{LOb}_{\mathrm{i}}+\mathrm{CF}_{\mathrm{add}}, \\
& \mathrm{LSf}_{\text {mul }, \mathrm{i}}=\mathrm{LOb}_{\mathrm{i}} \times \mathrm{CF}_{\text {mul }},
\end{aligned}
$$

In Equations (15) and (16), $\left(\mathrm{LSf}_{\mathrm{add}, \mathrm{i}}\right)$ and $\left(\mathrm{LSf}_{\mathrm{mul}, \mathrm{i}}\right)$ represent the values of the variables of the future climate scenarios and were computed using the multiplicative and additive arithmetic formulation of 
the change factors. Lob $b_{i}$ presents the locally scaled observed values of the measured meteorological variable of a single measuring station or the mean measured time series for the ith time step.

\section{Results}

\subsection{Correlation between GCMs and Data Observed In Situ}

With the aim of avoiding the systematic error between GCMs and data observed in situ (such as cumulative monthly precipitation and mean monthly temperature), the correlation of each downscaled GCM with the gauge-based data was assessed separately at the Rasht climate station in the Vakhsh River Basin for the 1966-2004 period.

The correlations between the gauge-based GCM data are represented in Figure 5. In each scatterplot of the GCMs, $R^{2}$ presents the coefficient of determination of the linear regression. From the scatterplot analysis, we found that the temperature correlation was considerably better than that of the precipitation (Figure 5). This finding was consistent with those reported by Anjum et al. [52] for the Swat River Basin in Pakistan, by Bokke et al. [79] for the Nile River Basin in Ethiopia, and by Fang et al. [80] for the Kaidu River Basin in China. The correlation outcomes of all the applied GCMs (GFDL-ESM2M, HadGEM2-ES, IPSL-CM5A-LR, MIROC, and NoerESM1-M) in the Vakhsh River Basin showed that the uncertainty of the precipitation was greater than that of the temperature. The GCM data had a comparatively stronger correlation with the observed data for the projected average monthly temperature. The average temperature showed almost identical accuracy to the maximum/minimum temperature. According to the execution of all models, the correlation coefficient between the results and the observations of the mean monthly temperature was higher than 0.99 for the 1966-2004 period. The correlation coefficient of the accumulated observed monthly precipitation and the GCMs data presented a value that was slightly higher than 0.95 for the 1966-2004 time period.

\subsection{Changes in Annual Precipitation and Temperature}

The mean annual temperature and precipitation projections compared to the baseline condition of two future time periods (2022-2060 and 2061-2099) under RCP4.5 and RCP8.5, coupled with the outputs of the five GCMs for the Vakhsh River Basin, are shown in Figure 6. The scatter plots in Figure 6 indicate the probable changes in the temperature of each GCM model and the GCM-based precipitation change rate in the Vakhah River Basin. All five selected GCMs (GFDL-ESM2M, HadGEM2-ES, IPSL-CM5A-LR, MIROC, and NoerESM1-M) showed an increasing pattern of mean annual temperature under RCP4.5 and RCP8.5 in all future time periods. The three GCM simulations mostly showed a decreasing trend in mean annual precipitation over the basin, but two GCMs (MIROC and GFDL-ESM2M) displayed an increasing tendency in mean annual precipitation during the future time period 2022-2060 under RCP4.5. The pattern of annual average precipitation of the HadGEM2-ES model showed a significant increasing trend compared to the GFDL-ESM2M model, and the other three GCM models indicated a decreasing trend during the first future time period (2022-2060). Among the five GCMs, the MIROC model showed a significant increasing trend and the IPSL-CM5A-LR model showed a significant decreasing trend in annual precipitation over two future time periods, 2022-2060 and 2061-2099, under RCPs 4.5 and 8.5. The current findings indicate that the probable mean annual precipitation varied in the range of uncertainty. Similar results were reported by Anjum et al. [52] for the Swat River Basin in Pakistan and by Zhang et al. [32] for the Xian River Basin in China. Regarding the mean annual precipitation, the range of variation generally decreased, and the mean annual temperature increased over time. Furthermore, the multi-model ensemble (MME) predicted a decreasing trend in mean annual precipitation (from $-4.46 \%$ to $-7.42 \%$ ) during the two future time periods under both RCPs in the Vakhsh River Basin. 

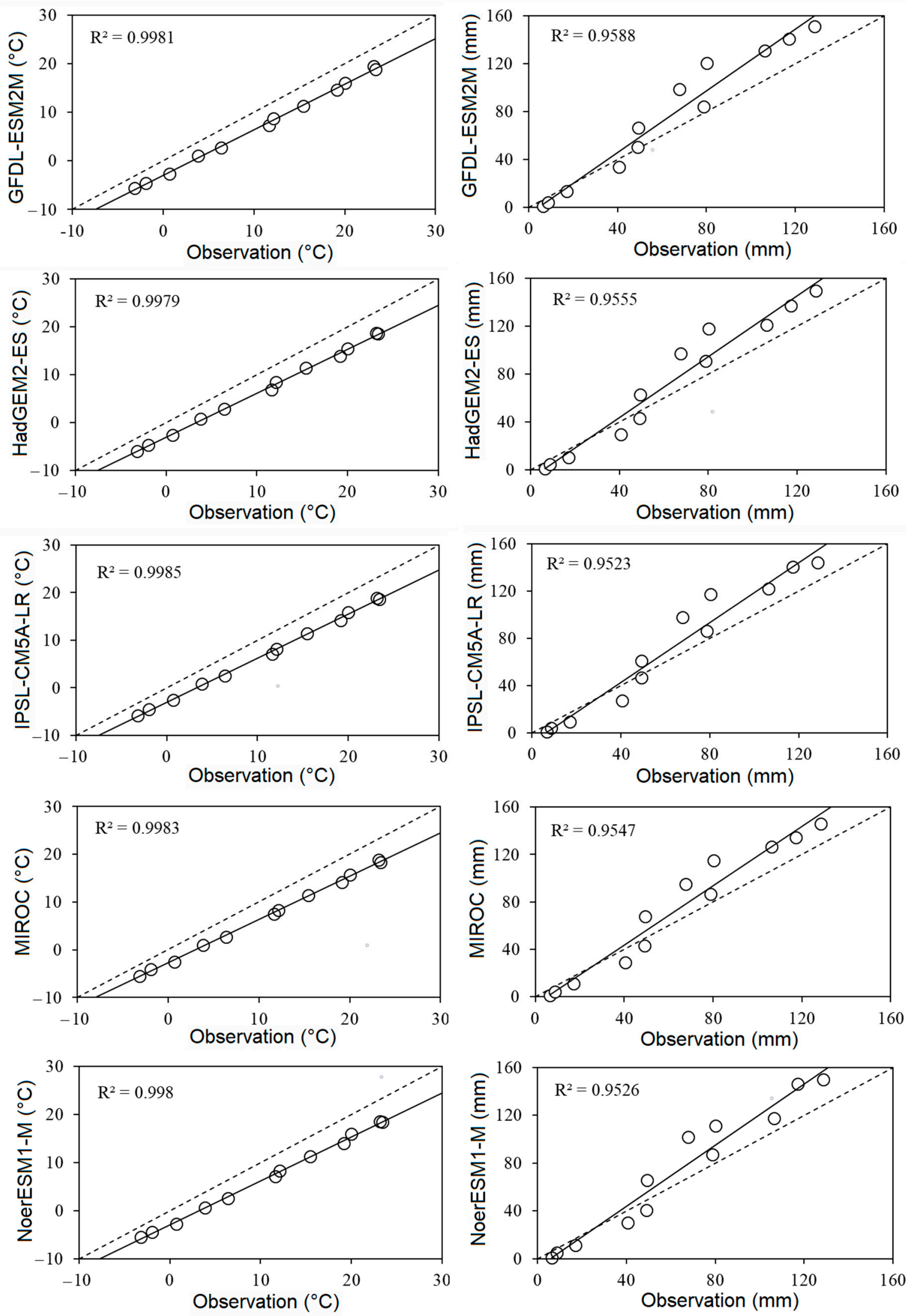

Figure 5. All GCM monthly mean temperature (figures on the left side) and accumulated precipitation (figures on the right side) from 1966 to 2004 at the Rasht climate station in the Vakhsh River Basin, Central Asia. 


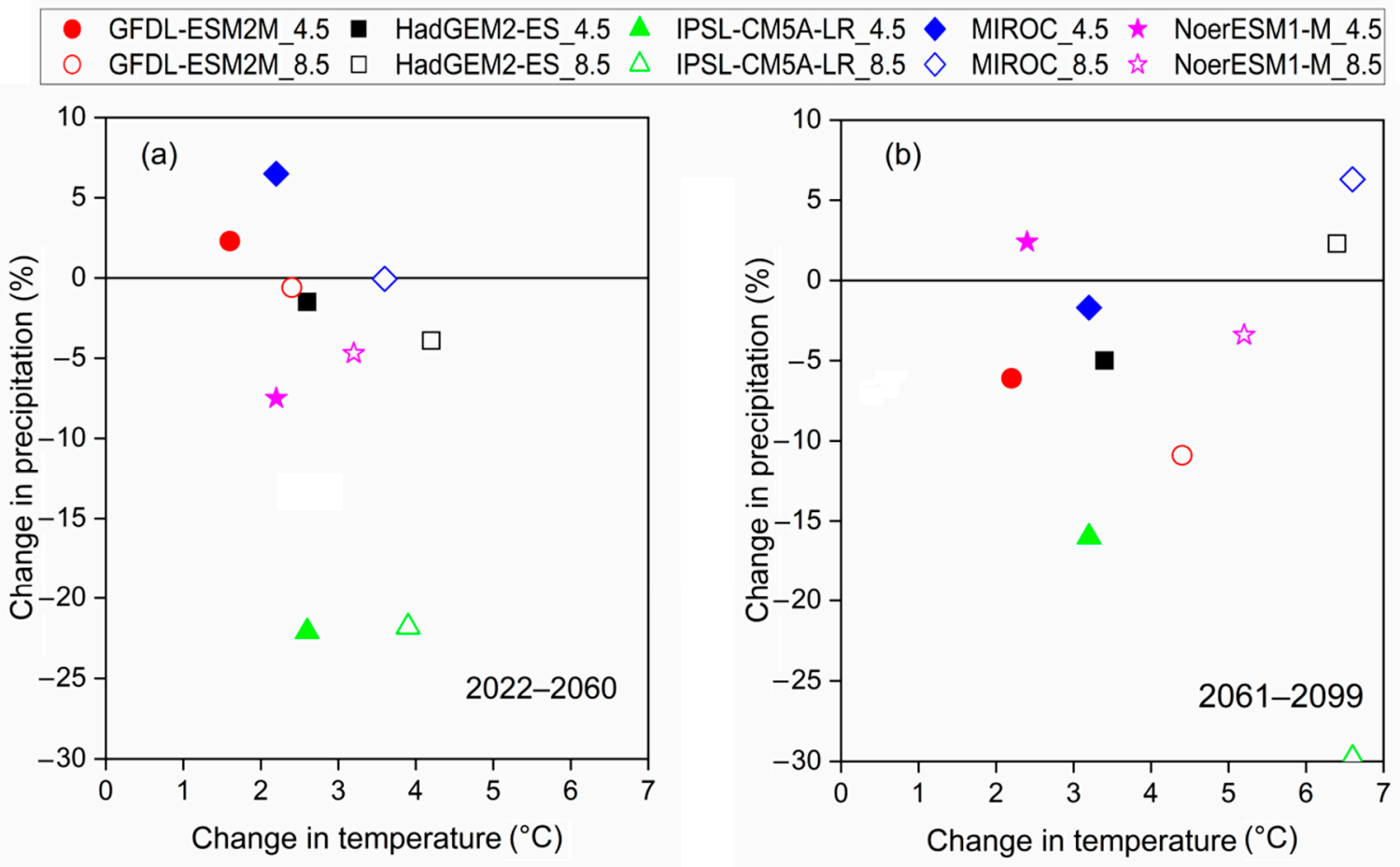

Figure 6. All GCM annual precipitation and temperature changes in the Vakhsh River Basin, Central Asia, under RCPs 4.5 and 8.5 in the (a) 2022-2060 and (b) 2061-2099 periods, relative to the base period (1966-2004).

The projection of the climate variables under RCP4.5 displayed alterations in the mean annual temperature and precipitation during the future time periods 2022-2060 and 2061-2099, where the precipitation could vary from $-22.1 \%$ to $6.5 \%$, and the temperature could rise from 1.6 to $2.5^{\circ} \mathrm{C}$. Hence, for the second future period, the precipitation may vary from $-16.0 \%$ to $-1.7 \%$ and temperature may rise from 1.9 to $3.1{ }^{\circ} \mathrm{C}$. Under RCP8.5, during the 2022-2060 future time period, the average annual precipitation is expected to decrease by $21-0.05 \%$, and the temperature may rise from 1.8 to $3.7^{\circ} \mathrm{C}$; in the case of the 2061-2099 time period, the annual precipitation could vary from $-29.8 \%$ to $5.3 \%$ and temperature may rise from 3.4 to $6.4{ }^{\circ} \mathrm{C}$. Comprehensively, under RCP8.5, temperature and precipitation depicted a wide range of uncertainties, which is shown in Figure 6.

Figure 7 shows the precipitation change rate of all five GCMs during the periods of 2022-2060 and 2061-2099 under RCPs 4.5 and 8.5. The HadGEM2-ES model, represented by the cyan color, had a relatively greater range of average performance than the other GCM models in the study area. The IPSL-CM5A-LR model, indicated with the pink color in Figure 7, showed a lower range than the average performance. The results show that the GFDL-ESM2M, MORIC, and NoerESM1-M models performed consistently under both RCPs during the two future time periods. 

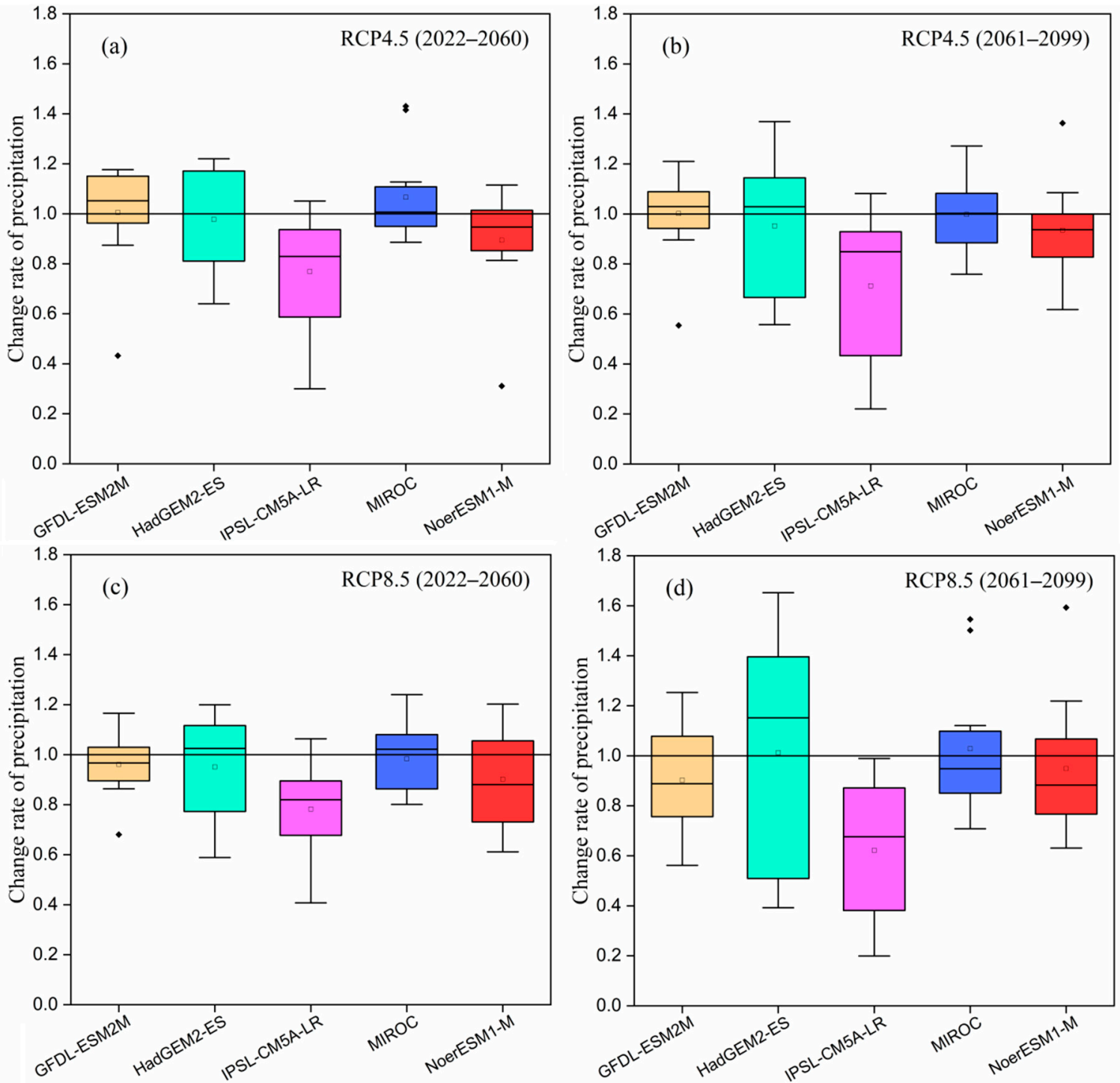

Figure 7. Box-and-whisker plots of the precipitation changes of the GCMs during the 2022-2060 and 2061-2099 periods under RCPs 4.5 and 8.5 in the Vakhsh River Basin, Central Asia.

\subsection{Changes in Future Seasonal Maximum/Minimum Temperature and Precipitation}

The seasonal changes in the average maximum/minimum temperature and precipitation during the future time periods of 2022-2060 and 2061-2099, with reference to the baseline condition, are presented in Table 2. In the winter season, the projected average precipitation for two GCMs (GFDL-ESM2M and MIROC) showed a decreasing trend, whereas the results of one GCM (HadGEM2-ES) showed a significant increasing trend in all future periods under both RCPs (RCP4.5 and RCP8.5). One of the GCMs (GFDL-ESM2M) revealed an increasing trend for the first future time period, while another GCM (NoerESM1-M) showed an increasing trend for the second future time period. The changes in the average winter precipitation varied from $-5.2 \%$ to $22.3 \%$ and from $-10.6 \%$ to $29.5 \%$ in the $2022-2060$ time period and from $-14.1 \%$ to $15.6 \%$ and from $-14 \%$ to $54.9 \%$ in the $2061-2099$ time period under RCP4.5 and RCP8.5, respectively. The changes in the spring precipitation showed an increasing tendency for two GCMs (GFDL-ESM2M and HadGEM2-ES) and a decreasing tendency for the three other GCMs (IPSL-CM5A-LR, MIROC, and NoerESM1-M) under both RCPs in all future time periods. The mean precipitation changes in the spring season ranged from $-10.9 \%$ (IPSL-CM5A-LR) to $9.1 \%$ (GFDL-ESM2M) and from $-4.7 \%$ (NoerESM1-M) to $2.3 \%$ (HadGEM2-ES) under RCP4.5, and under RCP8.5, from -5.6\% (NoerESM1-M) to 9.2\% (GFDL-ESM2M) and -13.1\% (IPSL-CM5A-LR) 
to $4.5 \%$ (HadGEM2-ES) in the respective future periods. In the summer season, under both RCPs, the decreasing tendency of mean precipitation was greater than in the other seasons; it decreased from $26.9 \%$ to $2.5 \%$, and might vary from $-57.1 \%$ to $26.4 \%$ at the end of this century. In the $2022-2060$ time period under RCP4.5 and RCP8.5 in the summer, the average precipitation changed from $-50.3 \%$ to $19.7 \%$ and $-47.8 \%$ to $4.2 \%$, respectively. Under both RCPs in the fall season, the mean precipitation for one GCM (MIROC) displayed a complete increase during the two future periods, and another GCM (NoerESM1-M) showed an increasing tendency (from $7.1 \%$ to $11 \%$ ) in the first future period under RCP8.5 and in the second future period under RCP4.5; however, a decreasing trend (from $8.2 \%$ to $10.3 \%$ ) was found in the 2022-2060 time period under RCP8.5 and in the 2022-2060 time period under RCP4.5. Furthermore, three GCMs (GFDL-ESM2M, HadGEM2-ES, and IPSL-CM5A-LR) generally indicated a decreasing trend in all of the future time periods. According to these three models, the respective mean precipitation in the fall season is expected to decrease from $8.6 \%$ to $23.2 \%, 10.4 \%$ to $25.4 \%$, and $11.2 \%$ to $32 \%$, respectively, and could vary from $-41.2 \%$ to $5.1 \%$ over both time periods. The seasonal scale analysis of the mean precipitation changes highlighted large uncertainties among the five GCMs in the various future time periods under RCP4.5 and RCP8.5, as evidenced by the presence of both increasing and decreasing tendencies. However, the MME predicted an increase in winter precipitation in the 2022-2060 and 2061-2099 time periods (from $0.42 \%$ to 5.1\% under RCPs 4.5 and 8.5) in the Vakhsh River Basin in Central Asia. The current findings in line with results of Omani et al. [13] and Ta et al. [81] where they used the CMIP5 MME for 16 GCMs and CMIP5 MME for 37 GCMs. Omani et al. [13] and Ta et al. [81] reported that winter precipitation is expected to increase in the Pamir-Alay mountain range in Central Asia. Previous studies have reported that both tropical and westerly circulation modes simultaneously impact the Central Asian climate, especially throughout the moist winter and spring seasons. In Central Asia, the weather types represent a regional expression of signs of tropical and extratropical circulation, which spread from the western and southern directions. Furthermore, previous studies indicate that hydroclimate conditions over Central Asia are strongly impacted by the location and strength of the westerly jet stream $[82,83]$.

The projected maximum temperature (Tmax) and minimum temperature (Tmin) showed a coherent rising tendency in all seasons. The probable changes in Tmax and Tmin under RCP4.5 in both future time periods are expected to vary from 1.5 to $3.4^{\circ} \mathrm{C}$ and from 1.5 to $3.1^{\circ} \mathrm{C}$ in winter and from 1.8 to $3.6^{\circ} \mathrm{C}$ and from 1.5 to $3.1{ }^{\circ} \mathrm{C}$ in spring, respectively. Under the same RCP scenario, the expected changes in Tmax and Tmin in both time periods in the summer season are $1.8-5.4^{\circ} \mathrm{C}$ and $1-3.3{ }^{\circ} \mathrm{C}$ and in the fall season are $2.1-4.5^{\circ} \mathrm{C}$ and $1.2-4{ }^{\circ} \mathrm{C}$, respectively. Under RCP8.5, the respective probable increases in Tmax and Tmin in both time periods range from 2.7 to $6.8^{\circ} \mathrm{C}$ and from 2.7 to $6.8^{\circ} \mathrm{C}$ (winter) and from 2.6 to $7.1^{\circ} \mathrm{C}$ and 2.1 to $6.1^{\circ} \mathrm{C}$ (spring) compared with the range from 2.9 to $8.9^{\circ} \mathrm{C}$ and from 1.1 to $6.8^{\circ} \mathrm{C}$ (summer) and from 3.4 to $7.9^{\circ} \mathrm{C}$ and from 1.3 to $7.1{ }^{\circ} \mathrm{C}$ (fall).

\subsection{Hydrological Modeling Results}

The simulation of the river discharge generated by applying the hydrological model is shown in Table 3. In this study, the SWAT-CUP tool was used to examine the sensitivity of the parameters, the uncertainty analysis, and the model calibration. The SWAT-CUP tool integrates procedures for several algorithms (Figure 3). In this study, the Sequential Uncertainty Fitting version 2 (SUFI-2) algorithm was selected to find parameters for baseflow simulation (GW QMN, GW_REVAP, REVAPMN, etc.), parameters for surface flow simulation (CN2, SOL_AWC, ESCO, etc.), and parameters for flow process line adjustment (ALPHA_BF, RCHRG_DP, etc.) for analysis based on experience and references $[84,85]$. Based on the statistical criteria of the $t$-stat and $p$-value, the sensitivity of each parameter and its relative significance were evaluated. The $t$-stat was computed from the coefficient of a variable in the multiple regression analysis divided by the standard error. A parameter was considered to be sensitive if the value of the coefficient was large in comparison to the standard error. The $p$-value was computed via comparison of the $t$-stat value with the Student's distribution table [86]. Table 3 shows the $t$-stat and $p$-values of the different effective parameters. 
Table 2. The possible alterations in the annual and seasonal average maximum temperature (Tmax), minimum temperature (Tmin), and precipitation (Pr) in the Vakhsh River Basin in Central Asia in the two future time periods for the winter (Wi), spring (Sp), summer (Su), fall (Fa), and annual (An) time scales.

\begin{tabular}{|c|c|c|c|c|c|c|c|c|c|c|c|c|c|c|c|c|c|}
\hline \multirow{2}{*}{ Scenario } & \multirow{2}{*}{ Period } & \multirow{2}{*}{ Model } & \multicolumn{5}{|c|}{$\Delta P(\%)$} & \multicolumn{5}{|c|}{$\Delta \operatorname{Tmax}\left({ }^{\circ} \mathrm{C}\right)$} & \multicolumn{5}{|c|}{$\Delta \operatorname{Tmin}\left({ }^{\circ} \mathrm{C}\right)$} \\
\hline & & & Wi & $\mathrm{Sp}$ & Su & Fa & An & Wi & $S p$ & Su & $\mathbf{F a}$ & An & Wi & Sp & Su & $\mathbf{F a}$ & An \\
\hline \multirow{10}{*}{ RCP4.5 } & \multirow{5}{*}{ 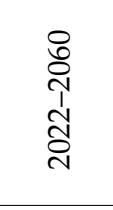 } & GFDL-ESM2M & 1.7 & 9.1 & 19.7 & -21.2 & 2.3 & 1.5 & 1.8 & 1.8 & 2.8 & 2.0 & 1.5 & 1.5 & 1.0 & 1.2 & 1.3 \\
\hline & & HadGEM2-ES & 22.3 & 0.8 & -20.4 & -8.6 & -1.5 & 2.3 & 2.6 & 4.0 & 3.1 & 3.0 & 2.6 & 1.8 & 2.5 & 2.2 & 2.3 \\
\hline & & IPSL-CM5A-LR & -3.8 & -10.9 & -50.3 & -23.2 & -22.1 & 1.7 & 2.6 & 3.5 & 3.4 & 2.8 & 1.8 & 2.2 & 2.6 & 3.2 & 2.5 \\
\hline & & MIROC & -5.2 & -0.6 & 10.5 & 21.5 & 6.5 & 2.0 & 2.4 & 2.2 & 2.1 & 2.2 & 2.2 & 2.2 & 2.6 & 2.2 & 2.3 \\
\hline & & NoerESM1-M & -4.0 & -7.7 & -29.5 & 11.0 & -7.5 & 2.0 & 2.8 & 2.3 & 2.3 & 2.3 & 2.0 & 2.3 & 2.0 & 2.3 & 2.2 \\
\hline & \multirow{5}{*}{$\begin{array}{l}\text { ò } \\
\text { iे } \\
\frac{1}{0} \\
\text { ते }\end{array}$} & GFDL-ESM2M & 6.3 & 1.6 & -13.5 & -18.8 & -6.1 & 2.4 & 2.6 & 2.7 & 2.8 & 2.6 & 2.7 & 1.9 & 1.7 & 1.3 & 1.9 \\
\hline & & HadGEM2-ES & 15.6 & 2.3 & -27.6 & -10.4 & -5.0 & 3.4 & 3.6 & 5.4 & 4.1 & 4.1 & 2.8 & 2.5 & 2.9 & 2.6 & 2.7 \\
\hline & & IPSL-CM5A-LR & -9.1 & -2.5 & -26.9 & -25.4 & -16.0 & 2.7 & 2.7 & 3.5 & 4.5 & 3.4 & 2.6 & 2.8 & 3.1 & 4.0 & 3.1 \\
\hline & & MIROC & -14.1 & -2.7 & -2.5 & 12.6 & -1.7 & 2.8 & 3.6 & 3.2 & 3.4 & 3.3 & 3.1 & 3.1 & 3.3 & 2.9 & 3.1 \\
\hline & & NoerESM1-M & 3.4 & -4.7 & -21.8 & -10.3 & -8.3 & 2.1 & 2.6 & 2.6 & 2.5 & 2.5 & 2.4 & 2.0 & 2.4 & 2.5 & 2.3 \\
\hline \multirow{10}{*}{ RCP8.5 } & \multirow{5}{*}{ 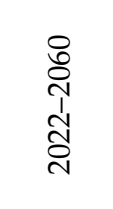 } & GFDL-ESM2M & -0.8 & 9.2 & 4.2 & -15.1 & -0.6 & 2.7 & 2.6 & 2.9 & 3.6 & 2.9 & 2.7 & 2.1 & 1.1 & 1.3 & 1.8 \\
\hline & & HadGEM2-ES & 29.5 & 3.6 & -37.3 & -11.2 & -3.9 & 4.5 & 3.7 & 5.7 & 4.6 & 4.6 & 4.5 & 2.7 & 4.0 & 3.8 & 3.7 \\
\hline & & IPSL-CM5A-LR & -3.2 & -4.3 & -47.8 & -32.0 & -21.8 & 3.1 & 3.6 & 4.7 & 5.3 & 4.1 & 3.1 & 3.2 & 3.8 & 4.5 & 3.7 \\
\hline & & MIROC & -10.6 & -1.5 & -3.6 & 15.5 & -0.05 & 3.1 & 4.0 & 3.5 & 3.5 & 3.5 & 3.4 & 3.7 & 4.0 & 3.4 & 3.6 \\
\hline & & NoerESM1-M & -8.6 & -5.6 & 3.8 & -8.2 & -4.7 & 3.4 & 3.4 & 3.3 & 3.4 & 3.4 & 3.5 & 2.8 & 2.9 & 2.7 & 3.0 \\
\hline & \multirow{5}{*}{$\begin{array}{l}\text { ò } \\
\text { iे } \\
\frac{1}{0} \\
\text { ते }\end{array}$} & GFDL-ESM2M & -9.7 & 2.0 & -25.1 & -10.9 & -10.9 & 4.7 & 4.7 & 6.3 & 5.9 & 5.4 & 4.0 & 3.5 & 3.1 & 2.9 & 3.4 \\
\hline & & HadGEM2-ES & 54.9 & 4.5 & -55.4 & 5.1 & 2.3 & 6.1 & 5.9 & 8.9 & 6.8 & 7.0 & 6.2 & 4.8 & 6.1 & 5.9 & 5.8 \\
\hline & & IPSL-CM5A-LR & -7.7 & -13.1 & -57.1 & -41.2 & -29.8 & 5.8 & 6.8 & 7.3 & 7.9 & 6.9 & 5.5 & 6.0 & 6.4 & 7.1 & 6.2 \\
\hline & & MIROC & -14.0 & -8.3 & 26.4 & 17.1 & 5.3 & 6.8 & 7.1 & 6.8 & 6.8 & 6.9 & 6.8 & 6.1 & 6.8 & 5.9 & 6.4 \\
\hline & & NoerESM1-M & 2.0 & -11.0 & -11.7 & 7.1 & -3.4 & 5.2 & 5.5 & 5.3 & 5.5 & 5.4 & 5.8 & 4.5 & 5.0 & 4.8 & 5.0 \\
\hline
\end{tabular}


Table 3. Parameters used for SWAT model calibration, the hydrological model determination of the effective parameters, and the sensitivity analysis in the Vakhsh River Basin, Central Asia.

\begin{tabular}{|c|c|c|c|c|c|c|}
\hline Parameters & Definition & Min & Max & Fitted Value & $t$-Stat & $p$-Value \\
\hline v_GWQMN.gw & $\begin{array}{l}\text { Threshold depth of water in the } \\
\text { shallow aquifer required for return } \\
\text { flow to occur (mm) }\end{array}$ & 0 & 1573 & 1193 & -0.79 & 0.43 \\
\hline v_GW_REVAP.gw & Groundwater "revap" coefficient & 0.09 & 0.24 & 0.16 & -1.59 & 0.11 \\
\hline v_REVAPMN.gw & $\begin{array}{c}\text { Threshold depth of water in the } \\
\text { shallow aquifer for "revap" to } \\
\text { occur (mm) }\end{array}$ & 418 & 1807 & 1377 & -2.18 & 0.03 \\
\hline v_RCHRG_DP.gw & Deep aquifer percolation fraction & 0.5 & 1 & 0.57 & -0.46 & 0.65 \\
\hline v_ALPHA_BF.gw & Baseflow alpha factor (days) & 0 & 1 & 0.67 & -10.96 & 0.00 \\
\hline r_CN2.mgt & $\begin{array}{l}\text { SCS runoff curve number to } \\
\text { moisture condition II }\end{array}$ & 0.76 & 1.13 & 1.07 & -0.29 & 0.76 \\
\hline r_SOL_AWC().sol & $\begin{array}{c}\text { Available water capacity of the soil } \\
\text { layer }\left(\mathrm{mm} \mathrm{H}_{2} \mathrm{O} / \mathrm{mm} \text { soil }\right)\end{array}$ & -0.15 & 0.25 & -0.04 & -0.16 & 0.88 \\
\hline r_SOL_K().sol & $\begin{array}{l}\text { Saturated hydraulic } \\
\text { conductivity }(\mathrm{mm} / \mathrm{h})\end{array}$ & -0.3 & 0.9 & 0.64 & -3.08 & 0.01 \\
\hline r_SOL_BD().sol & Moist bulk density $\left(\mathrm{g} / \mathrm{cm}^{3}\right)$ & -0.2 & 0.9 & 0.20 & -3.76 & 0.001 \\
\hline $\mathrm{v} \_\mathrm{CH}$ _K2.rte & $\begin{array}{l}\text { Effective hydraulic conductivity in } \\
\text { main channel alluvium }\end{array}$ & 0 & 80 & 75.6 & 49.61 & 0.001 \\
\hline v_ESCO.hru & $\begin{array}{l}\text { Soil evaporation } \\
\text { compensation factor }\end{array}$ & 0.79 & 0.98 & 0.8 & 0.72 & 0.47 \\
\hline r_OV_N.hru & $\begin{array}{l}\text { Manning's " } \mathrm{n} \text { " value for } \\
\text { overland flow }\end{array}$ & 0.2 & 0.7 & 0.30 & -0.40 & 0.69 \\
\hline r_HRU_SLP.hru & Average slope steepness $(\mathrm{m} / \mathrm{m})$ & -0.7 & 0.2 & 0.07 & -2.76 & 0.01 \\
\hline r__SLSUBBSN.hru & Average slope length (m) & 0.1 & 0.6 & 0.45 & 1.18 & 0.24 \\
\hline
\end{tabular}

$\mathrm{v}_{-}$: : parameter value is replaced by a given value or absolute change; $\mathrm{r}_{-}$: parameter value is multiplied by $1+\mathrm{a}$ given value or the relative change.

In the hydrological modeling, the calibration was checked along with the sensitivity of the model parameters such as snow, groundwater recharge, soil, evaporation, and basin slope. In the first step, the model was calibrated without considering the different elevation bands for the 14 year period (2000-2013). The first three years of the period were selected as the warm-up period for the hydrological model. The period from 2003 to 2008 was considered the calibration period, and from 2009 to 2013 was the model validation period. The parameter ranges under different objective functions were adjusted to obtain better results; however, in this mountainous study area, the SWAT-CUP did not provide satisfactory results based solely on modifying the parameter ranges. Initially, the monthly discharge from 2003 to 2013 time period was calibrated, without applying the elevation band approach for the Darband discharge station. The uncertainty performance of the $\mathrm{p}$-factor, $\mathrm{r}$-factor, and the values of $\mathrm{R}^{2}$ and NS were $0.48,0.72,0.41$, and 0.04 , respectively. It was essential to split the data into elevation bands in the mountainous watershed before fixing the range of parameters in the calibration procedure. We improved the simulation results after zoning (five elevations), as shown in Figures 8 and 9 and Table 4.

The model calibration and validation results, as well as a comparison of the observed and simulated flows at daily and monthly time intervals, are described in Table 4 . The quantification of the goodness of calibration and the uncertainty performance were derived from the $\mathrm{p}$-factor and $\mathrm{r}$-factor. For discharge, the recommended values for the $\mathrm{r}$-factor of $<1.5$ and $\mathrm{p}$-factor of $>0.7$ or 0.75 are acceptable, depending on the sufficiency of the input calibrating data and the scale of the project [84]. In this study, the p-factor and the r-factor values were 0.87 and 1.15 , and 0.86 and 0.83 for the calibration of the daily and monthly time steps, respectively. For the validation period, the values of the $r$-factor and the p-factor were 0.82 and 0.84 , and 0.86 and 1.08 for the daily and monthly simulations, respectively. Figure 8 presents the daily calibration and validation of the hydrological model during the periods of 2003-2008 and 2009-2013. The values of $R^{2}$, NSE, PBIAS, RSR, and MSE for the calibration period were $0.79,0.78,5.3 \%, 0.47$, and 6.4 at the daily time scale, respectively, and similarly, for the validation period, $0.81,0.79,10.8 \%, 0.45$, and 6.7 , respectively. At the monthly time step, the values of $R^{2}$, NSE, 
PBIAS, RSR, and MSE for the calibration period were $0.93,0.92,4.6 \%, 0.29$, and 2.1, respectively, and for the validation period were $0.92,0.90,6.4 \%, 0.31$, and 2.8 , respectively (Figure 9). For the monthly time step, the model simulations presented excellent performance, with high NS (over 0.90) and $\mathrm{R}^{2}$ (over 0.90) values.

Statistical coefficients such as the p-factor and the r-factor showed that during the calibration and validation periods at the daily and monthly time scales, the semi-distributed SWAT model generated good statistical results. As expected, the model performed slightly better in the calibration period than in the period of validation. The calibration and validation results were slightly better for the monthly time scales than for the daily time scales. A comparison of the observed and simulated discharge and the 95\% prediction uncertainty (95PPU) bandwidth indicated that the well-calibrated hydrological model could effectively simulate monthly and daily streamflow under different RCPs in the Vakhsh River Basin.
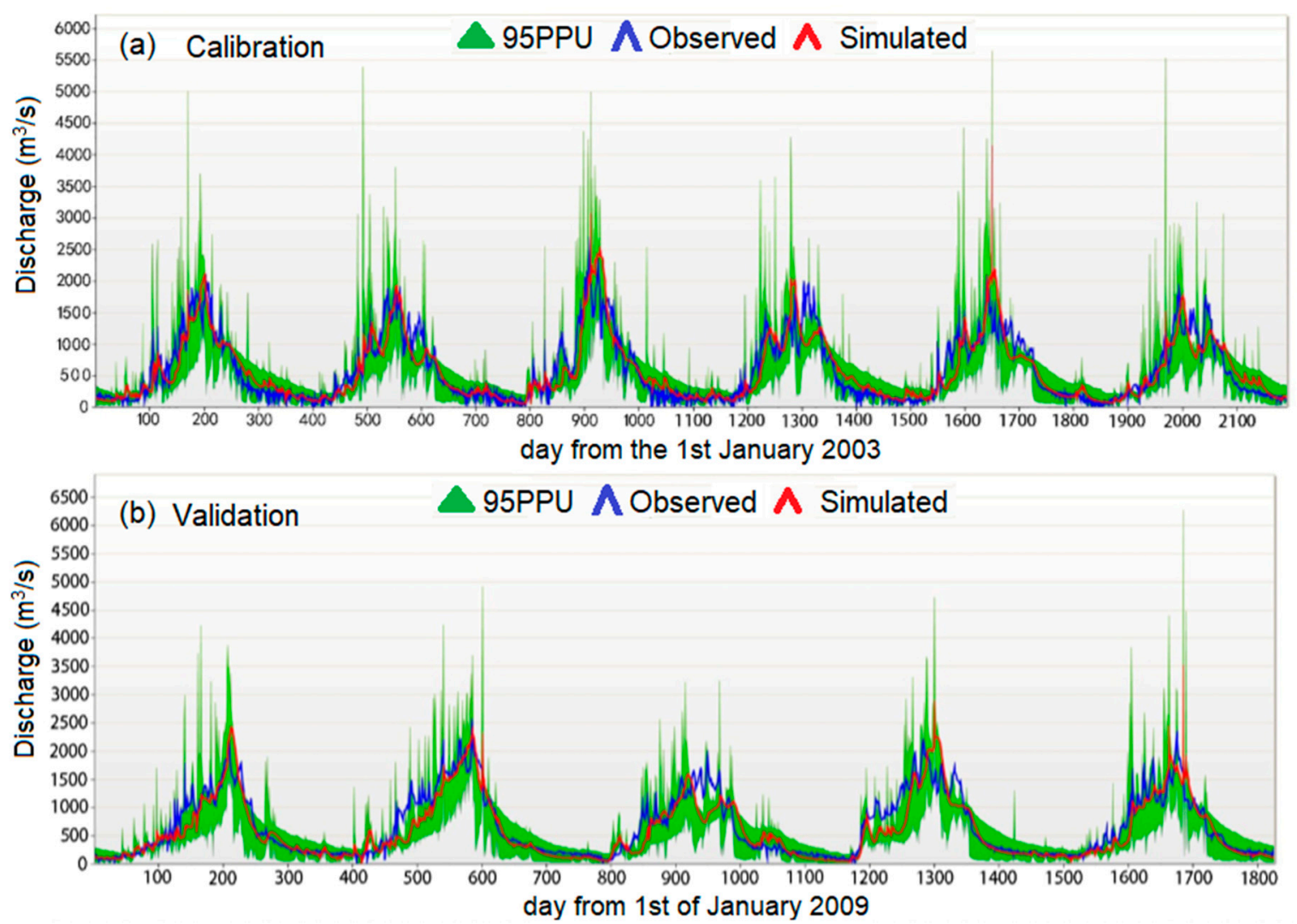

Figure 8. (a) Daily calibration (2003-2008) and (b) validation (2009-2013) using elevation band (EB) method in the application of the SWAT-CUP tool to the Darband discharge station in the Vakhsh River Basin in Central Asia. The observed discharge data (blue lines) are presented along with the prediction uncertainty (green range) and a set of 1000 simulations (red lines). 95PPU: 95\% prediction uncertainty. 

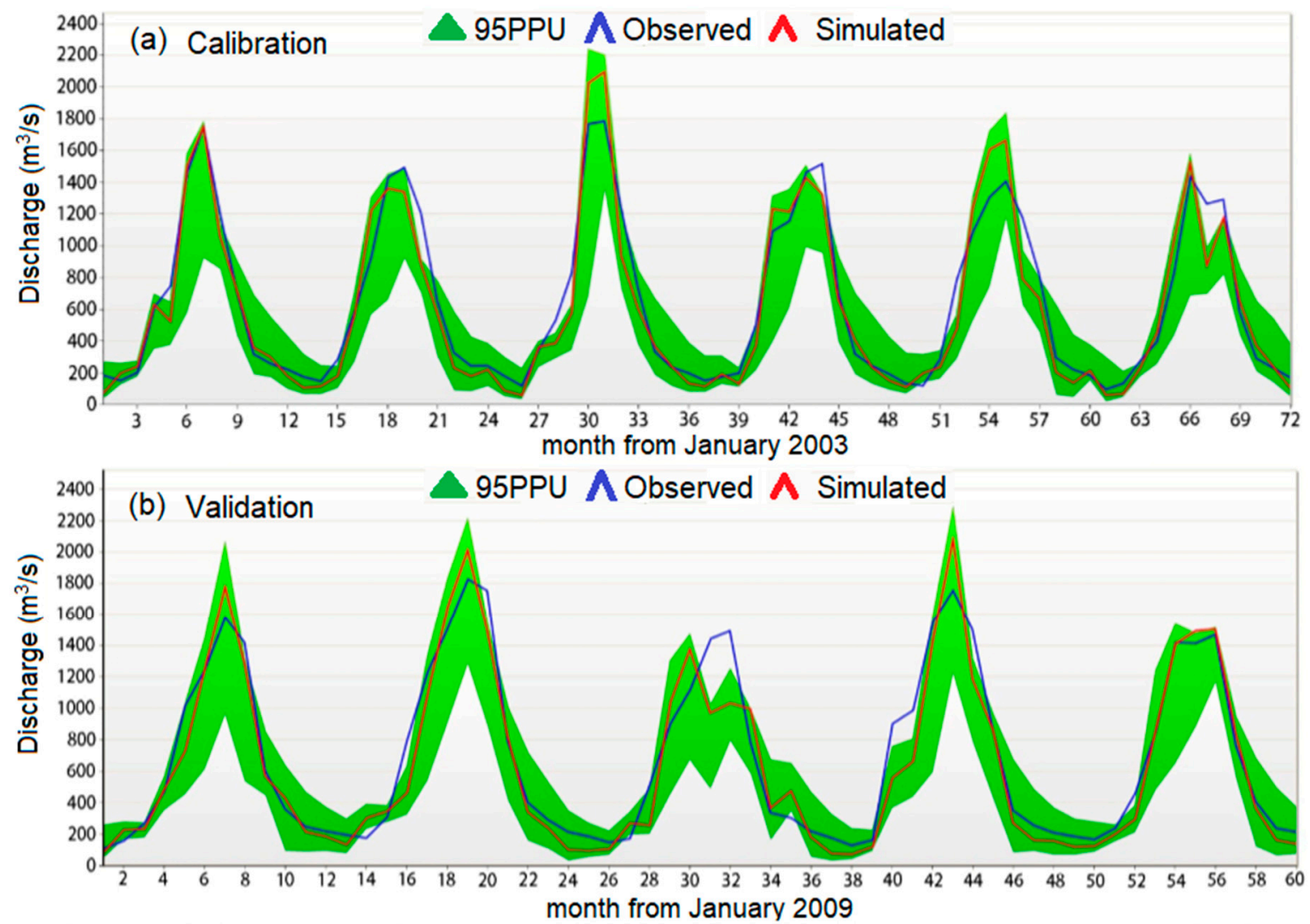

Figure 9. (a) Monthly calibration (2003-2008) and (b) validation (2009-2013) with the elevation band (EB) method in the application of the SWAT-CUP tool at the Darband discharge station in the Vakhsh River Basin in Central Asia. The observed discharge data (blue lines) are presented along with the prediction uncertainty (green range) and a set of 1000 simulations (red lines). 95PPU: 95\% prediction uncertainty.

Table 4. The statistics of a comparison of the observed monthly and daily calibration and validation data for the SWAT model with the simulation band based on the p-factor and r-factor at the Darband discharge gauging station in the Vakhsh River Basin (VRB), used to estimate the model performance. NSE: Nash-Sutcliffe efficiency; $\mathrm{R}^{2}$ : coefficient of determination; PBIAS: percentage bias; MSE: mean square error; RSR: root-mean-square error standard deviation ratio.

\begin{tabular}{ccccc}
\hline Factors and Statistical Indices & \multicolumn{2}{c}{ Monthly } & \multicolumn{2}{c}{ Daily } \\
\hline p-factor & 0.86 & 0.82 & 0.87 & 0.86 \\
r-factor & 0.83 & 0.84 & 1.15 & 1.08 \\
R $^{2}$ & 0.93 & 0.92 & 0.79 & 0.81 \\
NSE & 0.92 & 0.90 & 0.78 & 0.79 \\
PBIAS & 4.6 & 6.4 & 5.3 & 10.8 \\
RSR & 0.29 & 0.31 & 0.47 & 0.45 \\
MSE & 2.1 & 2.8 & 6.4 & 6.7 \\
\hline
\end{tabular}

\subsection{Projected Effect of Climate Change on Streamflow}

\subsubsection{Future Changes in the Annual and Seasonal Streamflow}

Table 5 shows the comparative variations in mean seasonal and annual flows in the future 2022-2060 and 2061-2099 time periods, relative to the baseline condition of the seasonal and annual average flows. The measured mean values of the river flow at the Darband gauging station in the Vakhsh River Basin were $170 \mathrm{~m}^{3} / \mathrm{s}$ in winter, $588 \mathrm{~m}^{3} / \mathrm{s}$ in spring, $1415 \mathrm{~m}^{3} / \mathrm{s}$ in summer, $425 \mathrm{~m}^{3} / \mathrm{s}$ in fall, and $1649 \mathrm{~m}^{3} / \mathrm{s}$ annually during the 2000-2013 period. Analysis of simulated river flows revealed 
that under the RCP4.5 and RCP8.5 scenarios, the alterations in the winter flows mostly increased. The changes in the winter flow could vary from $-23.1 \%$ to $29.7 \%$ and from $-21.1 \%$ to $-63.9 \%$ in all projected time periods under these RCPs. It is expected that the spring flow could increase by $25 \%$ to $61.4 \%$ under RCP4.5 and by $27.3 \%$ to $119.6 \%$ under RCP8.5 in the entire projected period (2022-2060 and 2061-2099). Variations in the summer river flow compared to the baseline condition are expected to vary from $-4.9 \%$ to $15.5 \%$ under RCP 4.5 and from $-12 \%$ to $22 \%$ under RCP8.5. In the entire projection period (2022-2060 and 2061-2099), the fall seasonal flows are expected to decrease by $4.3 \%$ to $32.9 \%$ under RCP4.5 and could vary from $-37.7 \%$ to $15.9 \%$ under RCP8.5. In all of the projected time periods, the mean annual river flows could range from $-21.1 \%$ to $25.6 \%$ under RCP4.5 and from $-3.3 \%$ to $52.3 \%$ under RCP8.5. In the second time period (2061-2099), the annual average flow was mostly predicted to increase under RCP4.5. In the 2061-2099 period, four GCMs (GFDL-ESM2M, HadGEM2-ES, IPSL-CM5A-LR, and MIROC) showed that annual average flow might increase by $2.3 \%$ to $25.6 \%$ under RCP4.5, while the other GCM (NoerESM1-M) showed that the annual average flow might decrease by 2.7\%. Under RCP8.5, three GCMs (GFDL-ESM2M, IPSL-CM5A, and NoerESM1-M) showed that annual average flow could vary from $0.3 \%$ to $3.3 \%$, while two GCMs (HadGEM2-ES and MIROC) showed a possible increase in the annual flow from 2.3\% to 7.8\% in the 2022-2060 time period. In the first future time period (2022-2060), under RCP4.5, four of the five GCMs (GFDL-ESM2M, IPSL-CM5A-LR, MIROC, and NoerESM1-M) showed a decrease in annual average flow in the Vakhsh River of $1.4 \%-6.4 \%$, while the other GCM (HadGEM2-ES) under RCP4.5 showed that the annual average flow might increase by 7.4\%. Under RCP8.5 in the 2061-2099 time period, the variation in the average annual flow indicated an increasing tendency and could vary from $17.5 \%$ to $52.3 \%$. In the second future time period (2061-2099), an increasing trend of the average annual flow for all GCMs was indicated under RCP8.5.

Table 5. Variations in the temporal projected average river flow at the annual and seasonal scales under RCP4.5 and RCP8.5 in the Vakhsh River Basin, Central Asia. Win: winter; Spr: spring; Sum: summer.

\begin{tabular}{cccccccccccccc}
\hline \multirow{2}{*}{ Model } & \multirow{2}{*}{ Period } & \multicolumn{9}{c}{ RCP4.5 } & \multicolumn{4}{c}{ RCP8.5 } \\
\cline { 3 - 11 } & & Win & Spr & Sum & Fall & Ann & Win & Spr & Sum & Fall & Ann \\
\hline \multirow{2}{*}{ GFDL-ESM2M } & $2022-2060$ & -13.9 & 27.1 & 4.4 & -25.8 & -2.1 & -6.3 & 27.3 & 5.3 & -37.7 & -2.8 \\
& $2061-2099$ & -12.1 & 38.6 & 5.7 & -23.0 & 2.3 & -12.5 & 70.3 & 8.5 & 3.5 & 17.5 \\
\hline \multirow{2}{*}{ HadGEM2-ES } & $2022-2060$ & 3.4 & 36.9 & 12.3 & -22.9 & 7.4 & 1.4 & 42.6 & 8.1 & -20.8 & 7.8 \\
& $2061-2099$ & 29.7 & 61.4 & 15.5 & -4.3 & 25.6 & 63.9 & 110.1 & 22.0 & 13.3 & 52.3 \\
\hline \multirow{2}{*}{ IPSL-CM5A-LR } & $2022-2060$ & -23.1 & 25.0 & -1.5 & -26.2 & -6.4 & -21.1 & 31.1 & -2.3 & -20.8 & -3.3 \\
& $2061-2099$ & -12.1 & 47.5 & -4.9 & -14.2 & 4.1 & -2.4 & 99.4 & -12.0 & -10.0 & 18.7 \\
\hline \multirow{2}{*}{ MIROC } & $2022-2060$ & -18.2 & 32.0 & 2.1 & -21.3 & -1.4 & -20.3 & 46.7 & -1.2 & -16.2 & 2.3 \\
& $2061-2099$ & -17.5 & 58.1 & -4.4 & -15.5 & 5.2 & 5.9 & 119.6 & -2.5 & 15.9 & 34.7 \\
\hline \multirow{2}{*}{ NoerESM1-M } & $2022-2060$ & -17.7 & 32.1 & -4.1 & -25.6 & -3.8 & -10.0 & 29.9 & 3.6 & -24.7 & -0.3 \\
& $2061-2099$ & -15.5 & 41.0 & -3.4 & -32.9 & -2.7 & 9.8 & 79.0 & -3.3 & -3.9 & 20.4 \\
\hline
\end{tabular}

\subsubsection{Future Changes in Extreme Discharges}

Prediction of the streamflow as well as of extreme flows is of great importance for flow control in the Vakhsh River. The Vakhsh River serves as a water source for agriculture, municipal uses, and hydropower production in Central Asian countries. We used a SWAT model to predict streamflow and extreme flows in the Vakhsh River. Figure 10a,b show the projected extreme flows (high and low flows) based on the multi-model ensemble in the two future time periods (2022-2060 and 2061-2099) relative to the baseline condition for Vakhsh River Basin under RCP4.5 and RCP8.5. 

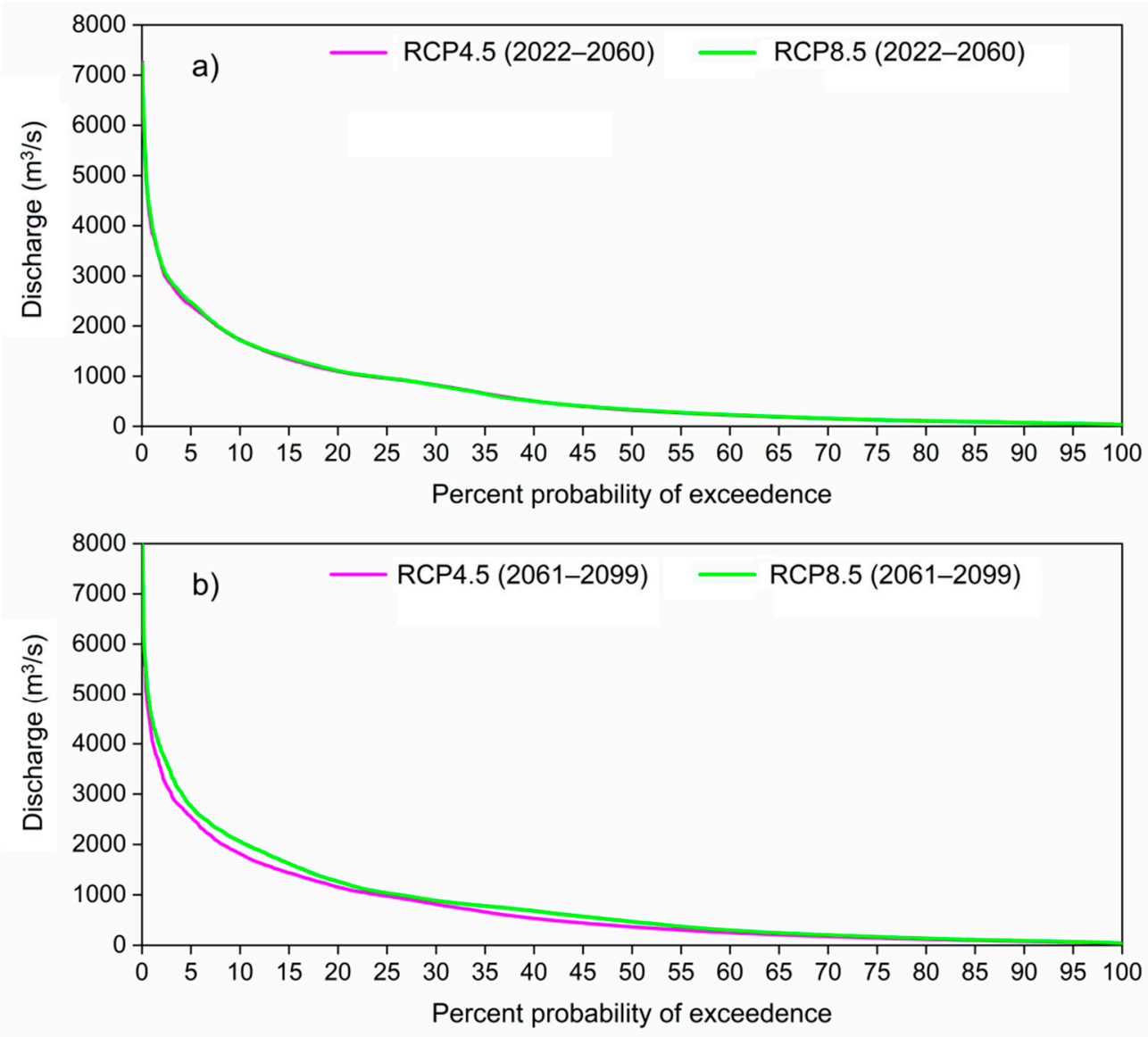

Figure 10. Flow duration curves of the study area at the Darband station based on the multi-model ensemble (MME) during (a) the 2022-2060 under RCP4.5 and RCP8.5 and (b) 2061-2099 periods under RCP4.5 and RCP8.5 in the Vakhsh River Basin, Central Asia.

The changes in the high flow (Q5) for all five GCMs under RCP4.5 and RCP8.5 showed an increasing tendency in both time periods (2022-2060 and 2061-2099), as shown in Table 6. The high flow (Q5) in the two future time periods may vary from $30.9 \%$ to $53.3 \%$ and from $41.3 \%$ to $59.2 \%$ under RCP4.5, and under RCP8.5 high flow may vary from $40.1 \%$ to $49.5 \%$ and from $41.4 \%$ to $78 \%$. For all five GCMs, the low flow (Q95) in the two future time periods may decrease from $51.4 \%$ to $57.2 \%$ and from $41 \%$ to $55.7 \%$ under both RCPs. However, the results showed that the changes in the median flow (Q50) were slightly different from the changes in extreme flows (Table 6). The analysis of the median flow in the 2022-2060 time period presented a decreasing behavior for all five GCMs under both RCPs. The median flow might decrease from $10.8 \%$ to $22.1 \%$ and from $6 \%$ to $24.1 \%$ under RCP4.5 and RCP 8.5 , respectively, in the 2022-2060 time period. It is expected that the median flow might vary from $-20.9 \%$ to $15.1 \%$ under RCP4.5 and might increase from $16.3 \%$ to $33.4 \%$ under RCP8.5 in the 2061-2099 time period. We revealed from the analysis of Q5, Q50, and Q95 compared to the low and median flows that the increase in the high flow could be greater. Similarly, the probable decrease in the low flow was greater than that in the median flow. We projected a significant increasing trend in high flow in Vakhsh River, which can be attributed to the rapidly melting snow and ice caused by constantly increasing air temperature. Increased high flow in the Vakhsh River implies a potential risk of flooding in the Vakhsh River Basin. Another phenomenon is that with increasing air temperatures, snowfall will decrease and rainfall will increase [13]. These variations may result in increased flooding during the early spring. Decreased low flow in the Vakhsh River implies that the risk of drought may also increase during fall season due to less meltwater contributing to runoff in the basin. 
Table 6. Relative changes in extreme (high and low) flows, as well as median flow, under the RCP4.5 and RCP8.5 scenarios in the Vakhsh River Basin, Central Asia.

\begin{tabular}{|c|c|c|c|c|c|c|c|}
\hline \multirow{2}{*}{ Model } & \multirow{2}{*}{ Scenario } & \multicolumn{2}{|c|}{ Q5 } & \multicolumn{2}{|c|}{ Q50 } & \multicolumn{2}{|c|}{ Q95 } \\
\hline & & $1 F P^{1}$ & $2 F P^{2}$ & $1 F P^{1}$ & $2 F^{2}$ & $1 F P^{1}$ & $2 F^{2}$ \\
\hline \multirow{2}{*}{ GFDL-ESM2M } & RCP4.5 & 40.7 & 49.2 & -18.2 & -16.1 & -54.9 & -52.1 \\
\hline & RCP8.5 & 43.9 & 66.9 & -24.1 & 16.3 & -55.0 & -47.9 \\
\hline \multirow{2}{*}{ HadGEM2-ES } & RCP4.5 & 53.3 & 59.9 & -10.8 & 15.1 & -51.7 & -41.3 \\
\hline & RCP8.5 & 49.5 & 78.0 & -6.0 & 24.1 & -51.4 & -41.0 \\
\hline \multirow{2}{*}{ IPSL-CM5A-LR } & RCP4.5 & 35.5 & 43.5 & -21.3 & -2.0 & -56.1 & -50.4 \\
\hline & RCP8.5 & 42.5 & 41.4 & -14.9 & 2.8 & -54.4 & -47.3 \\
\hline \multirow{2}{*}{ MIROC } & RCP4.5 & 37.9 & 43.3 & -19.5 & -10.8 & -55.0 & -53.7 \\
\hline & RCP8.5 & 40.1 & 57.3 & -12.7 & 33.4 & -53.8 & -42.9 \\
\hline \multirow{2}{*}{ NoerESM1-M } & RCP4.5 & 30.9 & 41.3 & -22.1 & -20.9 & -57.2 & -55.7 \\
\hline & RCP8.5 & 41.2 & 55.3 & -19.2 & 20.2 & -55.7 & -44.7 \\
\hline
\end{tabular}

${ }^{1}$ First future period (2022-2060); ${ }^{2}$ second future period (2061-2099).

\subsubsection{Discharge and Snowmelt Changes under Future Scenarios and Shifts in the Peak Flows}

Snow melting is essential in mountainous snow-covered basins. Figure 11 shows the changes in snowmelt for the 2020-2060 and 2061-2099 time periods under RCP4.5 and RCP8.5 for the five GCMs. In the two future time periods under both RCPs, an increasing snowmelt tendency was indicated. However, the significance of an increasing snowmelt trend varied from month to month. For instance, from October to June, the snowmelt presented a slightly increasing trend under both RCPs in both future time periods. In July and August, snowmelt may increase significantly compared with the other months in both time periods under both RCPs. In the Vakhsh River Basin, the months of March and April are warmer than those of May and June; however, snowmelt had a stronger increasing tendency in March and April than in May and June for all five GCMs under both RCPs in the two future time periods. Figure 11 shows that the Vakhsh River flow rate has great seasonal variability between winter and summer. It indicates that the Vakhsh is a snow- and glacier-fed river. Omani et al. [13] projected that under RCP8.5, at least $41 \%$ to $2 \%$ of the Vakshsh River Basin glaciers will remain. The multi-model ensemble under RCP4.5 and RCP8.5 scenarios projected that across the Vakhsh River Basin, by 2100, no glaciers shallower than 65 and 98 m.w.e will survive [13]. We conclude that increasing snowmelt in the future may be caused by the continuous increasing trend of air temperatures in the region, which will influence the water cycle and flow regime in the Vakhsh River.

In the two future time periods, by considering the average monthly discharge, the peak flow was estimated in the Vakhsh River under the RCP4.5 and RCP8.5 scenarios (Figure 12). The mean monthly discharge in the first time period showed an increasing trend in the months of April to June and a slight decreasing tendency in the months of August to May for all five GCMs under RCP4.5 and RCP8.5. Under both RCPs, in the 2061-2099 future time period, the mean monthly discharge increased for all five GCMs in the months February to July. The mean monthly discharge mostly showed a decreasing trend in the months of August to January under both RCPs in the second future time period. Under RCP4.5 in the first future time period, the mean monthly peak discharge was $1978 \mathrm{~m}^{3} / \mathrm{s}$ in June for GFDL-ESM2M, $2020 \mathrm{~m}^{3} / \mathrm{s}$ in June for HadGEM2-ES, $1942 \mathrm{~m}^{3} / \mathrm{s}$ in June for IPSL-CM5A-LR, $1814 \mathrm{~m}^{3} / \mathrm{s}$ in June for MIROC, and $1665 \mathrm{~m}^{3} / \mathrm{s}$ in June for NoerESM1-M under RCP8.5 for the same future time period; corresponding values of $2059 \mathrm{~m}^{3} / \mathrm{s}$ in June for GFDL-ESM2M, $1973 \mathrm{~m}^{3} / \mathrm{s}$ in June for HadGEM2-ES, $1900 \mathrm{~m}^{3} / \mathrm{s}$ in June for IPSL-CM5A-LR, $1743 \mathrm{~m}^{3} / \mathrm{s}$ in June for MIROC, and $1857 \mathrm{~m}^{3} / \mathrm{s}$ in June for NoerESM1-M were obtained compared to the baseline mean monthly peak discharge of $1534 \mathrm{~m}^{3} / \mathrm{s}$ in the month of July. In the 2061-2099 future time period under RCP4.5, the mean monthly peak discharge was $1996 \mathrm{~m}^{3} / \mathrm{s}$ in June for GFDL-ESM2M, $2049 \mathrm{~m}^{3} / \mathrm{s}$ in June for HadGEM2-ES, $1898 \mathrm{~m}^{3} / \mathrm{s}$ in June for IPSL-CM5A-LR, $1701 \mathrm{~m}^{3} / \mathrm{s}$ in June for MIROC, and $1706 \mathrm{~m}^{3} / \mathrm{s}$ in June for NoerESM1-M. 
Accordingly, in the 2061-2099 future time period under RCP8.5, the mean monthly peak discharge was $2123 \mathrm{~m}^{3} / \mathrm{s}$ in June for GFDL-ESM2M, $2577 \mathrm{~m}^{3} / \mathrm{s}$ in June for HadGEM2-ES, $1903 \mathrm{~m}^{3} / \mathrm{s}$ in May for IPSL-CM5A-LR, and $1701 \mathrm{~m}^{3} / \mathrm{s}$ in June for MIROC, and $1873 \mathrm{~m}^{3} / \mathrm{s}$ in May for NoerESM1-M compared to the baseline mean monthly peak discharge of $1534 \mathrm{~m}^{3} / \mathrm{s}$ in the month of July.
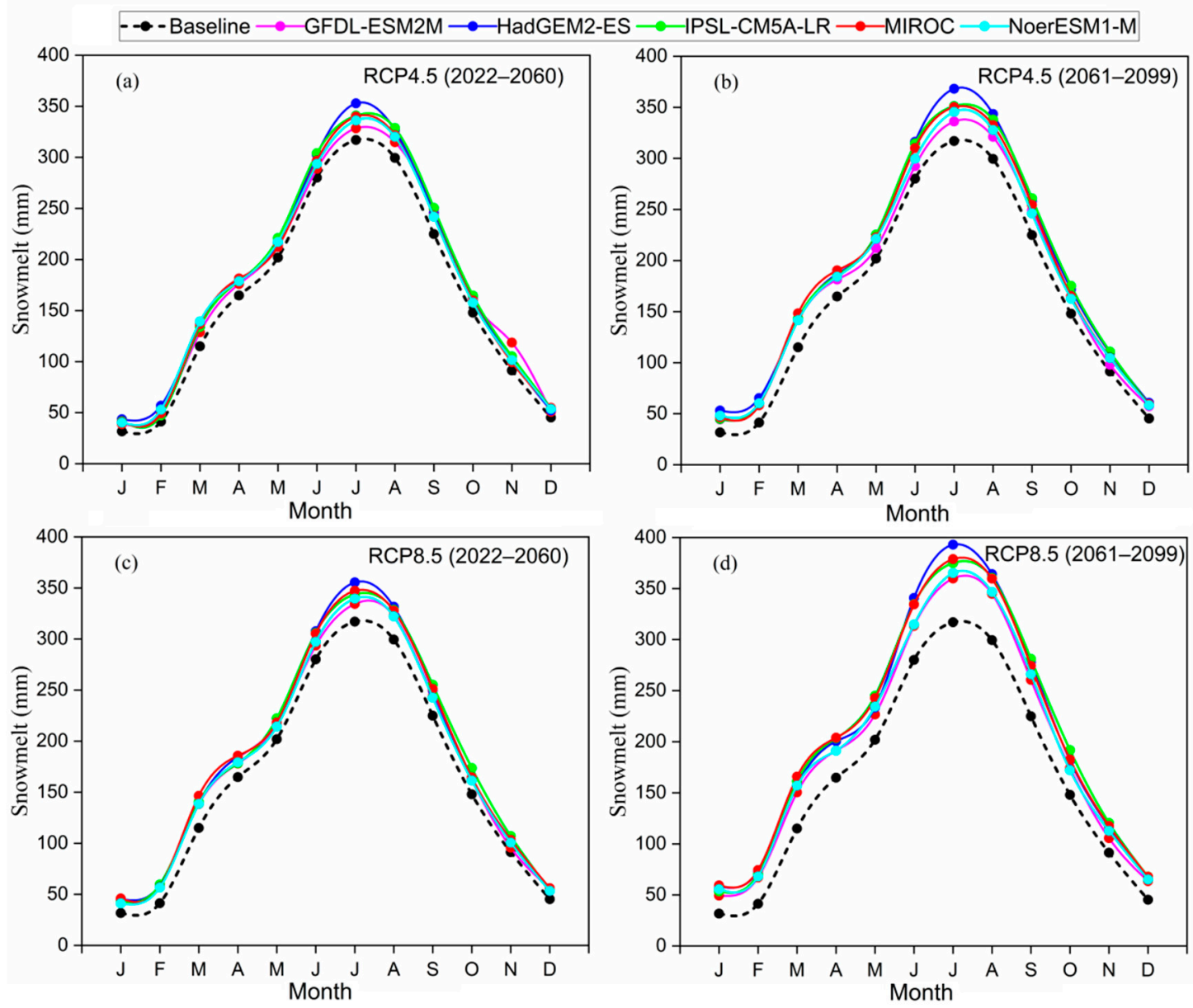

Figure 11. The projected monthly snowmelt during the 2022-2060 and 2061-2099 periods for the five GCMs under (a,b) RCP4.5 and (c,d) RCP8.5 in the Vakhsh River Basin, Central Asia.

Figure 13 shows the projected seasonal and annual flows at the Darband hydrological station. Clear variability in the seasonal and annual flows was found. Overall, a decreasing trend was indicated in the winter season (December-February) in both future time periods (2022-2060 and 2061-2099) under RCPs 4.5 and 8.5. In the spring season (March-May), all GCMs showed a relatively larger increasing tendency during the two future time periods of 2022-2060 and 2061-2099. A mix of increasing and decreasing trends was indicated in the summer season (June-August) in both RCPs. In the fall season (September-November), results of all GCMs indicated a relatively larger decreasing trend in both future time periods under both RCPs, except in the second future time period (2061-2099) under RCP8.5, in which two GCMs (HadGEM2-ES and MIROC) showed an increasing trend. Under RCP4.5, the mean annual flow predicted a decreasing tendency in the first future time period (2022-2060), while it predicted an increasing tendency in the second future time period (2061-2099). All GCMs showed an increasing trend in average annual flow at the end of the 21st century under RCP8.5. Under RCP4.5, the simulated flow of four GCM indicated an increasing trend in average annual flow in the 2061-2099 future time period. In the fall and winter seasons, all GCMs indicated a generally decreasing trend; hence, in summer and spring, all GCMs mostly showed an increasing trend in average flow during the 2022-2060 and 2061-2099 future time period under RCPs 4.5 and 8.5. Simulated results 
from MME showed an increasing trend in annual average flow in the two future time periods under both RCPs. The MME indicated a decreasing trend of the fall and winter flows during the 2022-2060 time period. MME also indicated that fall and winter flow at the end of the 21st century is expected to increase under both RCPs. According to the MME results, summer and spring flow is expected to increase in the near and far future time periods under both RCPs.
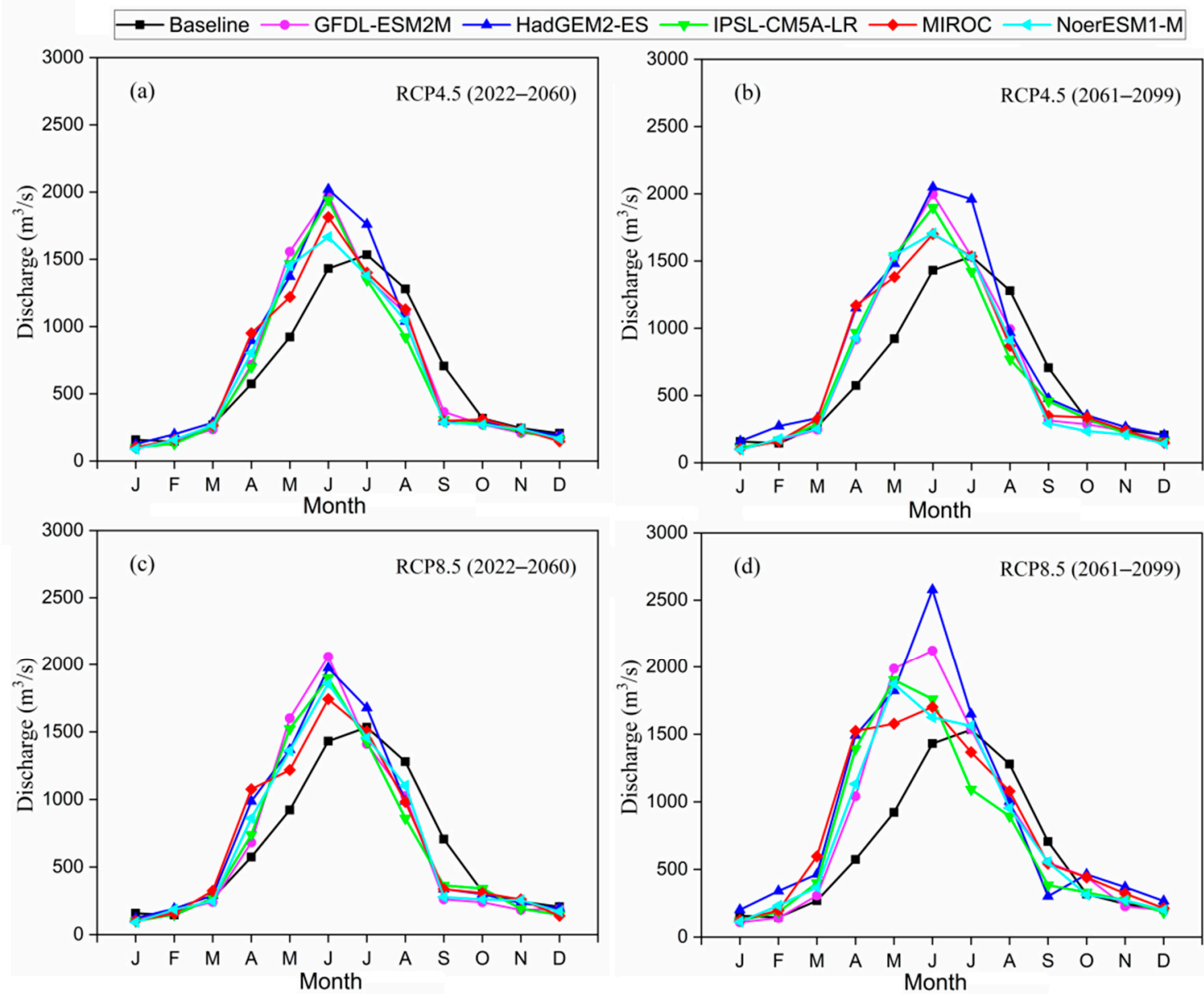

Figure 12. Monthly simulated discharge during the 2022-2060 and 2061-2099 time periods for the five GCMs under (a,b) RCP4.5 and (c,d) RCP8.5 in the Vakhsh River Basin, Central Asia.

We revealed from this analysis that in the two future time periods (2022-2060 and 2061-2099) under RCP4.5 and RCP8.5, compared to the baseline condition, January was the month with the lowest mean monthly discharge. In general, discharge exhibited an increasing tendency, which suggested that for downstream regions, more water resources will be available in the future. Discharge increased in spring and summer seasons in all future time periods; similarly, a significant decreasing tendency was indicated in the months of August and September under both RCPs. Under both RCPs and in both future time periods, the monthly peak discharge could shift from the month of July to June for all GCMs (mean monthly peak discharge for the baseline). Moreover, the mean monthly peak discharge could shift to late spring (month of May) for two GCMs (IPSL-CM5A-LR and NoerESM1-M) in the 2061-2099 time period compared to the baseline mean monthly discharge in the months of July. In this scenario, the streamflow increases and the peak flow shifts earlier because of earlier snowmelt caused by global warming. 

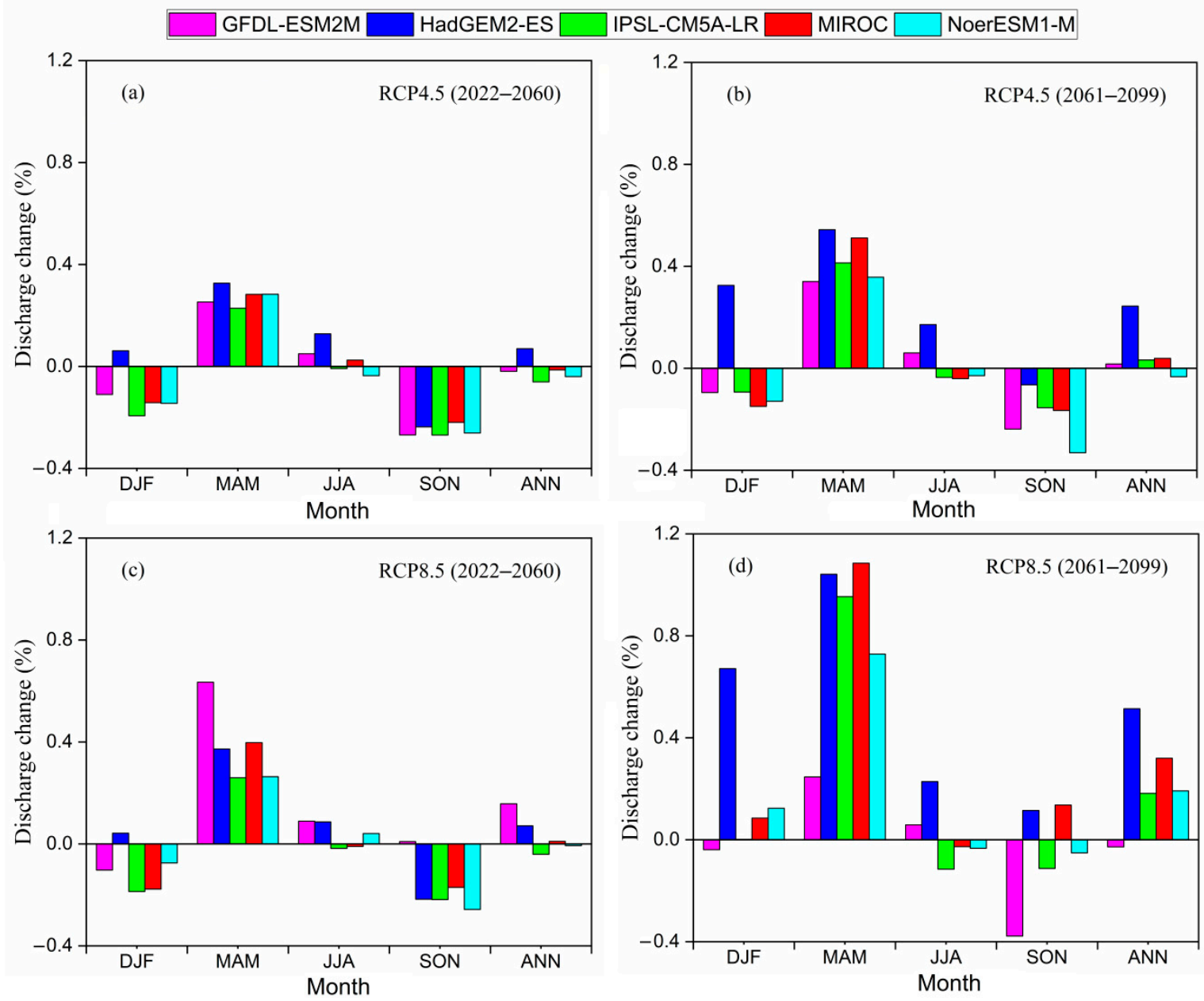

Figure 13. Seasonal and annual changes in the simulated discharge for five GCMs during the 2022-2060 and 2061-2099 time periods compared to the baseline period under (a,b) RCP4.5 and (c,d) RCP8.5 in the Vakhsh River Basin, Central Asia. ANN: annual.

\section{Discussion}

The Vakhsh River is the second largest tributary of the Amu Darya River after the Panj River. The climate of the basin is continental under the influence of the westerly wind, leading to significant seasonal changes in temperature and precipitation [87]. These changes are due to the mountainous topography of the basin, which has a very high local contrast $[18,88]$. The elevation ranges from 302 to $7050 \mathrm{~m}$ above sea level, and mountains occupy nearly $90 \%$ of the basin's area; it is the most vulnerable territory in Central Asia to hydroclimatic changes [89]. Furthermore, the world's largest mountain systems neighbor Tajikistan-the Himalayas on the north-east and the Tian Shan on the south-east. In addition, westward Tajikistan is open to wet Caspian and Mediterranean winds in winter. In summer, the south-western parts of the basin are strongly affected by the dry heat waves from the deserts of Uzbekistan, Turkmenistan, and Afghanistan.

In the mountain region of the Central Asia, the large amount of precipitation leads to a substantial accumulation of snow during the winter and spring season. The stream flow increases rapidly with the beginning of the snow melting period in March and April. The Vakhsh River Basin receives its maximum precipitation in winter and spring, which results in a clear temporal separation in accumulation of the snow and the time of the peak flow. The Vakhsh River is characterized by a seasonal cycle of river flow with maximum flow in the summer season (Figure 2). Summer runoff of the upstream catchments of the Central Asian rivers is controlled by the melting of snow and glaciers, which, in glacierized catchments, contributes up to $50 \%$ of the seasonal flow [90]. 
The downscaled precipitation and maximum/minimum temperature estimates from the five GCMs were in good agreement with the measurement-based data under the baseline condition (1966-2004). The product of multi GCMs of the Inter-Sectoral Impact Model Intercomparison Project (ISI-MIP) was used to assess the influences of the climate variation on the hydrological regimes, considered a suitable representative [2,91,92]. The meteorological data from ten climate stations and streamflow data from one hydrological station were used in this study. We analyzed the possible consequence of projected climate variation on interseasonal and annual water flow, as well as snowmelt in the VRB. We studied the responses of hydrological processes such as discharge and extreme and median flows to climate variation. The temporal impacts of the projected climate change were assessed by coupling a well-calibrated semi-distributed hydrological model (SWAT) with the results of the five GCMs under two greenhouse gas emission scenarios (RCP4.5 and RCP8.5). The effect of topography was corrected by applying the elevation band (temperature lapse rate and precipitation lapse rate) approach in this study, which improved the simulation results. We presented the results of the streamflow calibration and validation for the Vakhsh River at daily and monthly time scales. Additionally, by using the SWAT-CUP tool, we studied the sensitivity and prediction uncertainty of the model parameters, which was necessary to evaluate the strength of the calibrated model.

The results of the five GCMs presented continuous warming over the VRB at the annual and seasonal scales in the middle and at the end of this century. This finding is consistent with the results of previous studies in the Central and South Asian regions, including the Pamir-Alay [13,93], the Tian Shan-Pamir-North Karakoram [20], the Himalayas [21], and the Tibetan Plateau [22].

The probable change in water flow (presented in Table 6) indicated that the imbalances in the future water resources will be more severe. It is expected that the wet and dry seasons in the basin will become more severe than those in the baseline period. We showed that these phenomena are predicted to be stronger under RCP8.5 than under RCP4.5. A possible reason for these alterations is that in the future, more meltwater will be produced in early summer and more snow will be replaced by rain. The typical changes will accelerate the convergence of water flows and raise the flooding frequency and intensity. One of the possible causes of the rising temperature upstream of the Amu Darya River Basin could be the rising concentration of aerosols and greenhouse gases in the regional atmosphere. Folini et al. [94] reported that aerosol emissions in the 20th century might increase, in association with the enormous population and industrialization growth. Similarly, Bollasina et al. [25] confirmed that in Asia, the concentration of atmospheric aerosols has increased steadily. Xin et al. [26] reported that over China and Central Asia, a rising trend in the concentration of aerosols in the atmosphere could cause a substantial rise in temperature. The mean annual precipitation over the VRB is expected to rise in the 2022-2060 future time period under RCP4.5, as evidenced by the results of two GCMs (GFDL-ESM2M and MIROC), as well as the two GCMs (HadGEM2-ES and MIROC) that indicated a rising trend of precipitation in the second time period (2061-2099) under RCP8.5. The remaining GCM models that were analyzed in this study showed a decreasing trend of mean annual precipitation in the two future periods under both RCPs. The winter mean precipitation had a lower decreasing trend than that of the summer and fall seasons. The summer mean precipitation exhibited a greater decreasing tendency than the other seasons in the two future periods. Similarly, in the Yellow and Xin River Basins in China [32,68], in the Middle East [33], and in the westerly-dominated region of South Asia, a decreasing trend of summer precipitation was indicated [34]. The increasing or decreasing propensity of winter precipitation varies from model to model. Two GCMs showing a rising trend of winter precipitation and resembling this analysis were reported by Luo et al. [35] for the Heihe River Basin and by Omani et al. [13] for the Pamir-Alay mountains in Central Asia. However, the patterns of seasonal variations in precipitation for three GCMs presented in the Vakhsh River Basin are contrary to those in reported for the Hunza River Basin of the Karakoram mountains [15] and the Jhelum River Basin of the Himalayan mountains [36]. Pendergrass et al. [95] reported that the global winter precipitation increased over the second half of the 20th century, and they attributed this to the role of increasing moisture counteracted by weakening circulation. Li et al. [27] pointed out that in Central Asia, at the 
end of 20th century, there was a persistent decreasing trend of annual precipitation, and Meng et al. [29] confirmed that precipitation might increase in the middle of the 21st century in the south of the Tian Shan mountains. The multi-model ensemble result projected a decrease in average annual precipitation during the 2022-2060 and 2061-2099 time periods under both RCPs in the VRB. Hence, the MME projected an increase in winter precipitation in the 2022-2060 and 2061-2099 time period under RCPs 4.5 and 8.5. The interannual and seasonal scale analyses of the mean precipitation changes presented large uncertainties among the GCMs, as evidenced by both increasing and decreasing tendencies under RCP4.5 and RCP8.5 in various future time periods. In the Asian region, these contradictions in our findings may be associated with the rising concentration of anthropogenic absorbing aerosols and the westerlies system $[25,94,96,97]$.

The analysis of the simulated Vakhsh River flows mostly described an increasing trend of the mean annual streamflow during the 2061-2099 time period under RCP4.5 and RCP8.5, as well as a decreasing trend during the 2022-2060 time period under RCP4.5 (Figure 13). Mostly, the increase and a lesser decrease of annual future flow may be attributed to the similar projection of the different GCM models for the total annual precipitation. Similarly, a decreasing/increasing tendency for the different future periods of annual river flow was indicated in an arid alpine catchment in Karakoram [98]. A study of the extreme flows such as high flow (Q5) and low flow (Q95), as well as the median flow (Q50) revealed that the probable decrease in the low flow is larger than that in the median flow, and a rise in the high flow might be larger compared to the median and low flows. In addition, it is expected that the average monthly peak discharge may shift to earlier in the summer season, from July to June, for the two future time periods under both RCP4.5 and RCP8.5 for almost all GCMs, which is mainly due to the slight rise in precipitation in the spring and winter seasons, as well as because of an earlier snowmelt caused by global warming. Similarly, due to earlier snowmelt, Siegfried et al. [99] and Sorg et al. [100] projected the impacts of climate changes on flow seasonality and concluded that less water will be available in the summer months in the Syr Darya River Basin in Central Asia. Olsson et al. [101] confirmed, from trend analysis, this shift in seasonality of flow and predicted a possible decreasing trend of annual flow in the Zarafshan River Basin in Central Asia. A similar shift in the discharge peak (July to June) was pointed out by Liu et al. [98] for the Yarkant River Basin in Central Asia; in contrast, Babur et al. [36] reported that the discharge peak could be delayed (July to August) in the Jhelum River Basin. These discrepancies in detections might be related to various projected climate models for in the winter and summer seasonal precipitation in Central Asia. We found that the average monthly peak discharge in the Vakhsh River Basin indicated a significant decreasing tendency in August and September for the 2022-2060 and 2061-2099 time periods under RCP4.5 and RCP8.5 for all five of the GCMs. In this study, most of the GCM model outputs along with the multi-model ensemble results showed that the summer water flow in the Vakhsh River is expected to increase at the end of the 21st century under the two studied greenhouse gas emissions scenarios. Increases in summer water flow in the Vakhsh River can be ascribed to the rapid melting snow and ice caused by continuously increasing air temperature. Meanwhile, the projection of summer water availability is essential for the downstream countries, such as Uzbekistan and Turkmenistan in Central Asia, to adapt the national agricultural strategies to anomalous hydroclimatic conditions.

\section{Conclusions}

In this study, the semi-distributed hydrological SWAT model was applied in two future time periods (2022-2060 and 2061-2099) under the RCP4.5 and RCP8.5 scenarios in order to evaluate the effects of probable climate variation on the Vakhsh River flow. For the current basin, in order to predict climate variation, the results of the five GCMs were downscaled. The hydrological model was calibrated using a semi-automated SWAT_CUP tool and was validated for the 2003-2008 and 2009-2013 periods at daily and monthly time scales. We assessed the strength of the calibrated model by applying sensitivity and uncertainty analyses. Additionally, this mountainous catchment was divided into five elevation zones, which enhanced the accuracy of simulated outflows. The results of 
the values of the p-factor, the r-factor, and the statistical indices (NSE, $\mathrm{R}^{2}, \mathrm{RSR}, \mathrm{MSE}$, and PBIAS) for both the calibration and validation periods indicated that the hydrological model, which was built for the VRB, was quite well calibrated and reliable for use for the prediction of the possible influences of the climate variation on the flows. The main findings of this work were as follows.

(1) Based on the values of uncertainty and statistical evaluation indices of the simulated streamflow, it is concluded that under altering climatic conditions in the Vakhsh River Basin in Central Asia, the hydrological SWAT model is reliable to simulate the streamflow.

(2) The maximum/minimum temperatures are expected to increase consistently in the future time periods of 2022-2060 and 2061-2099 relative to the baseline condition (1966-2004) under both RCP4.5 and RCP8.5.

(3) The results of three GCMs indicated a decreasing tendency of annual average precipitation (from $-1.7 \%$ to $-16.0 \%$ under RCP4.5 and from $-3.4 \%$ to $-29.8 \%$ under RCP8.5). Under RCP8.5, two GCMs (HadGEM2-ES and MIROC) indicated an increase (from $2.3 \%$ to $5.3 \%$ ) in the average annual precipitation in the 2061-2099 time period. Among the five GCMs, the IPSL-CM5A-LR model showed a significant decreasing trend in annual precipitation over two future time periods, 2022-2060 and 2061-2099, under RCPs 4.5 and 8.5. In winter, the GCMs mostly showed a decreasing trend; however, the HadGEM2-ES model showed a significant increasing trend during two future periods under RCPs 4.5 and 8.5 in winter. The current findings indicate that the probable mean annual precipitation varied in the range of uncertainty. The range of variation in average annual precipitation generally decreased. The multi-model ensemble (MME) predicted a decrease in mean annual precipitation (from $-4.46 \%$ to $-7.42 \%$ ) during the two future time period and under both RCPs. However, the MME predicted an increase in winter precipitation in the 2022-2060 and 2061-2099 time periods (from $0.42 \%$ to 5.1\% under RCPs 4.5 and 8.5 ).

(4) Modeled flow results for almost all five GCMs revealed an increasing trend in average annual flow in the 2061-2099 future time period under RCP4.5 and RCP8.5, except for one GCM (NoerESM1-M) under RCP4.5 which indicated a decreasing trend. Generally, the seasonal variation of the two future periods under both RCPs showed a clear decrease in average flow during fall and winter and increasing trends in spring and summer. Simulated results of the multi-model ensemble indicated an increasing trend of annual average flow in the far (2061-2099) future time period under both RCP4.5 (6.90\%) and RCP8.5 (28.73\%). For the annual average flow in the near (2022-2060), RCP4.5 (-1.25\%) showed opposite trends to RCP8.5 (0.73\%). From the aspect of seasonal variation, under both RCPs, the MME indicated a decreasing trend of the fall and winter flows in the near future time period (from $-24.06 \%$ to $-24.36 \%$ and from $-11.25 \%$ to $-13.92 \%$ ). However, in fall and winter seasons, flows are expected to increase in the end of the 21st century under both RCPs (3.75\% and $12.75 \%)$. The MME revealed an increasing trend in summer and spring flows during the future time periods 2022-2060 and 2061-2099 under both RCPs 4.5 and 8.5 (from $1.72 \%$ to $2.65 \%$ and from $30.59 \%$ to $95.69 \%$ ). In this study, uncertainty in flow simulation existed because we treated the ice melt of glaciers as snowmelt in the SWAT model. In the GCM models, uncertainties also exist, which are propagated into SWAT. The streamflow, snowmelt simulation, and results description could be influenced by GCM uncertainties.

(5) Analysis of the flow duration curves revealed, for all GCMs, a possible increase in the high flows projected under both RCPs for the two future time periods. However, in the basin, the low flow was projected to decrease under RCP4.5 and RCP8.5 in the 2022-2060 and 2061-2099 time periods compared to the baseline condition (1966-2004). We found that the high flow was projected to increase more strongly in the future compared to the median and low flows. The possible decrease in the low flow was higher than the decrease in the median flow.

(6) It is expected that snowmelt might increase continuously with increasing temperature, and the average monthly peak discharge in the Vakhsh River Basin might shift to earlier in the summer season, from July to June, while a significant decreasing tendency in the average monthly peak 
discharge was found in August and September for the two future time periods under both the RCP4.5 and RCP8.5 scenarios.

The findings of the current research might be useful for the formulation of new water resource management guidelines and adaptation strategies to climate change in current ungauged mountainous catchments. Additionally, these findings might be helpful for making new planning schemes for irrigation in downstream countries, such as Uzbekistan and Turkmenistan, as well as for the sustainable design and administration of water resources for constructing hydropower plants in upstream countries, such as Tajikistan and Kyrgyzstan.

Author Contributions: All authors were involved in the intellectual part of this paper. X.C. and T.L. designed and supervised this research. A.G. conducted the major data processing and modeling works and wrote the manuscript. N.G. helped in the data arrangement. M.N.A. and M.R. revised the manuscript structure. All authors read and approved the final manuscript.

Funding: This research was funded by the Strategic Priority Research Program of Chinese Academy of Sciences, Pan-Third Pole Environment Study for a Green Silk Road (Grant No. XDA20060303), the International Cooperation Project of the National Natural Science Foundation of China (Grant No. 41761144079), the Xinjiang Tianchi Hundred Talents Program (Grant No. Y848041), and the project of the Research Center of Ecology and Environment in Central Asia (Grant No. Y934031).

Acknowledgments: The authors are thankful to the Ministry of Energy and Water Resources of the Republic of Tajikistan and the Agency of Hydrometeorology of the Committee for Environmental Protection under the Government of the Republic of Tajikistan for providing the data for this research work.

Conflicts of Interest: The authors declare no conflicts of interest.

\section{References}

1. Arheimer, B.; Donnelly, C.; Lindström, G. Regulation of snow-fed rivers affects flow regimes more than climate change. Nat. Commun. 2017, 8, 62. [CrossRef] [PubMed]

2. Jiang, Z.; Li, W.; Xu, J.; Li, L. Extreme precipitation indices over China in CMIP5 models. Part I: Model evaluation. J. Clim. 2015, 28, 8603-8619. [CrossRef]

3. Piao, S.; Ciais, P.; Huang, Y.; Shen, Z.; Peng, S.; Li, J.; Zhou, L.; Liu, H.; Ma, Y.; Ding, Y. The impacts of climate change on water resources and agriculture in China. Nature 2010, 467, 43. [CrossRef]

4. Zhao, G.; Tian, P.; Mu, X.; Jiao, J.; Wang, F.; Gao, P. Quantifying the impact of climate variability and human activities on streamflow in the middle reaches of the Yellow River basin, China. J. Hydrol. 2014, 519, 387-398. [CrossRef]

5. Schlüter, M.; Savitsky, A.G.; McKinney, D.C.; Lieth, H. Optimizing long-term water allocation in the Amudarya River delta: A water management model for ecological impact assessment. Environ. Modell. Softw. 2005, 20, 529-545. [CrossRef]

6. Jalilov, S.-M.; Keskinen, M.; Varis, O.; Amer, S.; Ward, F.A. Managing the water-energy-food nexus: Gains and losses from new water development in Amu Darya River Basin. J. Hydrol. 2016, 539, 648-661. [CrossRef]

7. ICWC. Interstate Commission for Water Coordination in Central Asia. Basin Water Organization of Amu Darya River Basin. Available online: http://www.icwc-aral.uz/bwoamuru.htm (accessed on 7 February 2019).

8. Barontini, S.; Grossi, G.; Kouwen, N.; Maran, S.; Scaroni, P.; Ranzi, R. Impacts of climate change scenarios on runoff regimes in the southern Alps. Hydrol. Earth Syst. Sci. Discus. 2009, 6, 3089-3141. [CrossRef]

9. Shiyin, L.; Yong, Z.; Yingsong, Z.; Yongjian, D. Estimation of glacier runoff and future trends in the Yangtze River source region, China. J. Glaciol. 2009, 55, 353-362. [CrossRef]

10. Jeelani, G.; Feddema, J.J.; van der Veen, C.J.; Stearns, L. Role of snow and glacier melt in controlling river hydrology in Liddar watershed (western Himalaya) under current and future climate. Water Resour. Res. 2012, 48. [CrossRef]

11. Bavay, M.; Grünewald, T.; Lehning, M. Response of snow cover and runoff to climate change in high Alpine catchments of Eastern Switzerland. Adv. Water Resour. 2013, 55, 4-16. [CrossRef]

12. Deng, H.; Chen, Y.; Wang, H.; Zhang, S. Climate change with elevation and its potential impact on water resources in the Tianshan Mountains, Central Asia. Glob. Planet. Chang. 2015, 135, 28-37. [CrossRef]

13. Omani, N.; Srinivasan, R.; Karthikeyan, R.; Reddy, V.; Smith, P.K. Impacts of climate change on the glacier melt runoff from five river basins. Trans. ASABE 2016, 59, 829-848. 
14. Mahmood, R.; Jia, S. Assessment of impacts of climate change on the water resources of the transboundary Jhelum River basin of Pakistan and India. Water 2016, 8, 246. [CrossRef]

15. Garee, K.; Chen, X.; Bao, A.; Wang, Y.; Meng, F. Hydrological modeling of the upper indus basin: A case study from a high-altitude glacierized catchment Hunza. Water 2017, 9, 17. [CrossRef]

16. Immerzeel, W.W.; Van Beek, L.P.; Bierkens, M.F. Climate change will affect the Asian water towers. Science 2010, 328, 1382-1385. [CrossRef]

17. White, C.J.; Tanton, T.W.; Rycroft, D.W. The impact of climate change on the water resources of the Amu Darya basin in central Asia. Water Res. Manag. 2014, 28, 5267-5281. [CrossRef]

18. Kayumov, A.; Novikov, V. (Eds.) The Third National Communication of the Republic of Tajikistan Under the United Nation Framework Convention on Climate Change; The Government of the Republic of Tajikistan: Dushanbe, Tajikistan, 2014; p. 155.

19. Konovalov, V. Extreme and Average Glacier Runoff in the Amudarya River Basin; Springer: Dordrecht, The Netherlands, 2009; pp. 371-376.

20. Luo, Y.; Wang, X.; Piao, S.; Sun, L.; Ciais, P.; Zhang, Y.; Ma, C.; Gan, R.; He, C. Contrasting streamflow regimes induced by melting glaciers across the Tien Shan-Pamir-North Karakoram. Sci. Rep. 2018, 8, 16470. [CrossRef]

21. Lutz, A.; Immerzeel, W.; Shrestha, A.; Bierkens, M. Consistent increase in High Asia's runoff due to increasing glacier melt and precipitation. Nat. Clim. Chang. 2014, 4, 587. [CrossRef]

22. You, Q.; Min, J.; Kang, S. Rapid warming in the Tibetan Plateau from observations and CMIP5 models in recent decades. Int. J. Climatol. 2016, 36, 2660-2670. [CrossRef]

23. Mannig, B.; Müller, M.; Starke, E.; Merkenschlager, C.; Mao, W.; Zhi, X.; Podzun, R.; Jacob, D.; Paeth, H. Dynamical downscaling of climate change in Central Asia. Glob. Planet. Chang. 2013, 110, 26-39. [CrossRef]

24. Reyer, C.P.; Otto, I.M.; Adams, S.; Albrecht, T.; Baarsch, F.; Cartsburg, M.; Coumou, D.; Eden, A.; Ludi, E.; Marcus, R. Climate change impacts in Central Asia and their implications for development. Reg. Environ. Chang. 2017, 17, 1639-1650. [CrossRef]

25. Bollasina, M.A.; Ming, Y.; Ramaswamy, V. Anthropogenic aerosols and the weakening of the South Asian summer monsoon. Science 2011, 334, 502-505. [CrossRef] [PubMed]

26. Xin, J.; Gong, C.; Wang, S.; Wang, Y. Aerosol direct radiative forcing in desert and semi-desert regions of northwestern China. Atmos. Res. 2016, 171, 56-65. [CrossRef]

27. Li, Z.; Chen, Y.; Fang, G.; Li, Y. Multivariate assessment and attribution of droughts in Central Asia. Sci. Rep. 2017, 7, 1316. [CrossRef]

28. Unger-Shayesteh, K.; Vorogushyn, S.; Farinotti, D.; Gafurov, A.; Duethmann, D.; Mandychev, A.; Merz, B. What do we know about past changes in the water cycle of Central Asian headwaters? A review. Glob. Planet. Chang. 2013, 110, 4-25. [CrossRef]

29. Meng, X.; Long, A.; Wu, Y.; Yin, G.; Wang, H.; Ji, X. Simulation and spatiotemporal pattern of air temperature and precipitation in Eastern Central Asia using RegCM. Sci. Rep. 2018, 8, 3639. [CrossRef]

30. Malsy, M.; aus der Beek, T.; Flörke, M. Evaluation of large-scale precipitation data sets for water resources modelling in Central Asia. Environ. Earth Sci. 2015, 73, 787-799. [CrossRef]

31. Liu, Q.; Cui, B. Impacts of climate change/variability on the streamflow in the Yellow River Basin, China. Ecol. Modell. 2011, 222, 268-274. [CrossRef]

32. Zhang, Y.; You, Q.; Chen, C.; Ge, J. Impacts of climate change on streamflows under RCP scenarios: A case study in Xin River Basin, China. Atmos. Res. 2016, 178, 521-534. [CrossRef]

33. Tabari, H.; Willems, P. Seasonally varying footprint of climate change on precipitation in the Middle East. Sci. Rep. 2018, 8, 4435. [CrossRef]

34. Ozturk, T.; Turp, M.T.; Türkeş, M.; Kurnaz, M.L. Projected changes in temperature and precipitation climatology of Central Asia CORDEX Region 8 by using RegCM4. 3.5. Atmos. Res. 2017, 183, $296-307$. [CrossRef]

35. Luo, K.; Tao, F.; Moiwo, J.P.; Xiao, D. Attribution of hydrological change in Heihe River Basin to climate and land use change in the past three decades. Sci. Rep. 2016, 6, 33704. [CrossRef]

36. Babur, M.; Babel, M.; Shrestha, S.; Kawasaki, A.; Tripathi, N. Assessment of climate change impact on reservoir inflows using multi climate-models under RCPs-The case of Mangla Dam in Pakistan. Water 2016, 8, 389. [CrossRef] 
37. Christensen, N.; Lettenmaier, D.P. A multimodel ensemble approach to assessment of climate change impacts on the hydrology and water resources of the Colorado River Basin. Hydrol. Earth Syst. Sci. Discus. 2006, 3, 3727-3770. [CrossRef]

38. Hayhoe, K.; Wake, C.P.; Huntington, T.G.; Luo, L.; Schwartz, M.D.; Sheffield, J.; Wood, E.; Anderson, B.; Bradbury, J.; DeGaetano, A. Past and future changes in climate and hydrological indicators in the US Northeast. Clim. Dyn. 2007, 28, 381-407. [CrossRef]

39. Velázquez, J.; Schmid, J.; Ricard, S.; Muerth, M.; Gauvin St-Denis, B.; Minville, M.; Chaumont, D.; Caya, D.; Ludwig, R.; Turcotte, R. An ensemble approach to assess hydrological models' contribution to uncertainties in the analysis of climate change impact on water resources. Hydrol. Earth Syst. Sci. 2013, 17, 565-578. [CrossRef]

40. Akhtar, M.; Ahmad, N.; Booij, M.J. Use of regional climate model simulations as input for hydrological models for the Hindukush-Karakorum-Himalaya region. Hydrol. Earth Syst. Sci. 2009, 13, 1075-1089. [CrossRef]

41. Schewe, J.; Heinke, J.; Gerten, D.; Haddeland, I.; Arnell, N.W.; Clark, D.B.; Dankers, R.; Eisner, S.; Fekete, B.M.; Colón-González, F.J. Multimodel assessment of water scarcity under climate change. Proc. Natl. Acad. Sci. USA 2014, 111, 3245-3250. [CrossRef]

42. Mueller Schmied, H.; Adam, L.; Eisner, S.; Fink, G.; Flörke, M.; Kim, H.; Oki, T.; Portmann, F.T.; Reinecke, R.; Riedel, C. Variations of global and continental water balance components as impacted by climate forcing uncertainty and human water use. Hydrol. Earth Syst. Sci. 2016, 20, 2877-2898. [CrossRef]

43. Olesen, J.E.; Carter, T.R.; Diaz-Ambrona, C.; Fronzek, S.; Heidmann, T.; Hickler, T.; Holt, T.; Minguez, M.I.; Morales, P.; Palutikof, J.P. Uncertainties in projected impacts of climate change on European agriculture and terrestrial ecosystems based on scenarios from regional climate models. Clim. Chang. 2007, 81, 123-143. [CrossRef]

44. Mango, L.M.; Melesse, A.M.; McClain, M.E.; Gann, D.; Setegn, S. Land use and climate change impacts on the hydrology of the upper Mara River Basin, Kenya: Results of a modeling study to support better resource management. Hydrol. Earth Syst. Sci. 2011, 15, 2245-2258. [CrossRef]

45. Van Liew, M.W.; Feng, S.; Pathak, T.B. Assessing climate change impacts on water balance, runoff, and water quality at the field scale for four locations in the heartland. Trans. ASABE 2013, 56, 883-900.

46. Fu, G.; Charles, S.P.; Chiew, F.H. A two-parameter climate elasticity of streamflow index to assess climate change effects on annual streamflow. Water Resour. Res. 2007, 43. [CrossRef]

47. Sankarasubramanian, A.; Vogel, R.M. Annual hydroclimatology of the United States. Water Resour. Res. 2002, 38. [CrossRef]

48. Her, Y.; Chaubey, I. Impact of the numbers of observations and calibration parameters on equifinality, model performance, and output and parameter uncertainty. Hydrol. Process. 2015, 29, 4220-4237. [CrossRef]

49. Chai, Y.; Li, Y.; Yang, Y.; Zhu, B.; Li, S.; Xu, C.; Liu, C. Influence of Climate Variability and Reservoir Operation on Streamflow in the Yangtze River. Sci. Rep. 2019, 9, 5060. [CrossRef]

50. Elliott, J.; Deryng, D.; Mueller, C.; Frieler, K.; Konzmann, M.; Gerten, D.; Glotter, M.; Florke, M.; Wada, Y.; Best, N.; et al. Constraints and potentials of future irrigation water availability on agricultural production under climate change. Proc. Natl. Acad. Sci. USA 2014, 111, 3239-3244. [CrossRef]

51. Bicknell, B.R.; Imhoff, J.C.; Kittle, J.L., Jr.; Donigian, A.S., Jr.; Johanson, R.C. Hydrological Simulation Program-FORTRAN. User's Manual for Release 11; United States Environmental Protection Agency: Washington, DC, USA, 1997.

52. Anjum, M.N.; Ding, Y.; Shangguan, D. Simulation of the projected climate change impacts on the river flow regimes under CMIP5 RCP scenarios in the westerlies dominated belt, northern Pakistan. Atmos. Res. 2019, 227, 233-248. [CrossRef]

53. Luo, M.; Meng, F.; Liu, T.; Duan, Y.; Frankl, A.; Kurban, A.; De Maeyer, P. Multi-model ensemble approaches to assessment of effects of local Climate Change on water resources of the Hotan River Basin in Xinjiang, China. Water 2017, 9, 584. [CrossRef]

54. Rouholahnejad, E.; Abbaspour, K.C.; Srinivasan, R.; Bacu, V.; Lehmann, A. Water resources of the Black Sea Basin at high spatial and temporal resolution. Water Resour. Res. 2014, 50, 5866-5885. [CrossRef]

55. Vaghefi, S.A.; Abbaspour, N.; Kamali, B.; Abbaspour, K.C. A toolkit for climate change analysis and pattern recognition for extreme weather conditions-Case study: California-Baja California Peninsula. Environ. Modell. Softw. 2017, 96, 181-198. [CrossRef] 
56. Hempel, S.; Frieler, K.; Warszawski, L.; Schewe, J.; Piontek, F. A trend-preserving bias correction-the ISI-MIP approach. Earth Syst. Dyn. 2013, 4, 219-236. [CrossRef]

57. Jarvis, A.; Reuter, H.I.; Nelson, A.; Guevara, E. Hole-Filled SRTM for the Globe Version 4. The CGIAR-CSI SRTM 90 m Database. 2008, 15, 25-54. Available online: http://srtm.csi.cgiar.org (accessed on 16 July 2019).

58. Arino, O.; Ramos Perez, J.J.; Kalogirou, V.; Bontemps, S.; Defourny, P.; Van Bogaert, E. Global Land Cover Map for 2009 (GlobCover 2009); European Space Agency: Paris, France; University College London: London, UK, 2012.

59. Food and Agriculture Organization; International Institute for Applied Systems Analysis; International Soil Reference and Information Centre. JRC: Harmonized World Soil Database (Version 1.2); FAO: Rome, Italy; IIASA: Laxenburg, Austria, 2012.

60. Arnold, J.G.; Srinivasan, R.; Muttiah, R.S.; Williams, J.R. Large area hydrologic modeling and assessment part I: Model development 1. JAWRA J. Am. Water Resour. Assoc. 1998, 34, 73-89. [CrossRef]

61. Arnold, J.G.; Moriasi, D.N.; Gassman, P.W.; Abbaspour, K.C.; White, M.J.; Srinivasan, R.; Santhi, C.; Harmel, R.; Van Griensven, A.; Van Liew, M.W. SWAT: Model use, calibration, and validation. Trans. ASABE 2012, 55, 1491-1508. [CrossRef]

62. Neitsch, S.L.; Arnold, J.G.; Kiniry, J.R.; Williams, J.R. Soil and Water Assessment Tool Theoretical Documentation Version 2009; Texas Water Resources Institute: College Station, TX, USA, 2011.

63. Ahl, R.S.; Woods, S.W.; Zuuring, H.R. Hydrologic calibration and validation of swat in a snow-dominated rocky mountain watershed, montana, USA 1. JAWRA J. Am. Water Resour. Assoc. 2008, 44, 1411-1430. [CrossRef]

64. Grusson, Y.; Sun, X.; Gascoin, S.; Sauvage, S.; Raghavan, S.; Anctil, F.; Sáchez-Pérez, J.-M. Assessing the capability of the SWAT model to simulate snow, snow melt and streamflow dynamics over an alpine watershed. J. Hydrol. 2015, 531, 574-588. [CrossRef]

65. Duan, Y.; Liu, T.; Meng, F.; Luo, M.; Frankl, A.; De Maeyer, P.; Bao, A.; Kurban, A.; Feng, X. Inclusion of Modified Snow Melting and Flood Processes in the SWAT Model. Water 2018, 10, 1715. [CrossRef]

66. Gao, Y.; Guo, Z.; Wang, D.; Zhang, Z.; Liu, Y. Multivariate Flood Risk Analysis at a Watershed Scale Considering Climatic Factors. Water 2018, 10, 1821. [CrossRef]

67. Hasan, M.M. WITHDRAWN: Application of Soil and Water Assessment Tool (SWAT) to Predict the Impact of Climate Change on Hydropower: A Case Study; Elsevier: Amsterdam, The Netherlands, 2018.

68. Zhang, Y.; Su, F.; Hao, Z.; Xu, C.; Yu, Z.; Wang, L.; Tong, K. Impact of projected climate change on the hydrology in the headwaters of the Yellow River basin. Hydrol. Proces. 2015, 29, 4379-4397. [CrossRef]

69. Abbaspour, K. SWAT-CUP 2012: SWAT Calibration and Uncertainty Programs-A User Manual; Eawag-Swiss Federal Institute of Aquatic Science and Technology: Dübendorf, Switzerland, 2015.

70. Abbaspour, K. User Manual for SWAT-CUP, SWAT Calibration and Uncertainty Analysis Programs; Eawag-Swiss Federal Institute of Aquatic Science and Technology: Duebendorf, Switzerland, 2007.

71. Yang, J.; Reichert, P.; Abbaspour, K.C.; Xia, J.; Yang, H. Comparing uncertainty analysis techniques for a SWAT application to the Chaohe Basin in China. J. Hydrol. 2008, 358, 1-23. [CrossRef]

72. Nash, J.E.; Sutcliffe, J.V. River flow forecasting through conceptual models part I-A discussion of principles. J. Hydrol. 1970, 10, 282-290. [CrossRef]

73. Moriasi, D.N.; Arnold, J.G.; Van Liew, M.W.; Bingner, R.L.; Harmel, R.D.; Veith, T.L. Model evaluation guidelines for systematic quantification of accuracy in watershed simulations. Trans. ASABE 2007, 50, 885-900. [CrossRef]

74. Touseef, M.; Chen, L.; Yang, K.; Chen, Y. Long-Term Rainfall Trends and Future Projections over Xijiang River Basin, China. Adv. Meteorol. 2020, 2020. [CrossRef]

75. Kilsby, C.G.; Jones, P.; Burton, A.; Ford, A.; Fowler, H.J.; Harpham, C.; James, P.; Smith, A.; Wilby, R. A daily weather generator for use in climate change studies. Environ. Modell. Softw. 2007, 22, 1705-1719. [CrossRef]

76. Akhtar, M.; Ahmad, N.; Booij, M.J. The impact of climate change on the water resources of Hindukush-Karakorum-Himalaya region under different glacier coverage scenarios. J. Hydrol. 2008, 355, 148-163. [CrossRef]

77. Hay, L.E.; Wilby, R.L.; Leavesley, G.H. A comparison of delta change and downscaled GCM scenarios for three mountainous basins in the United States 1. JAWRA J. Am. Water Resour. Assoc. 2000, 36, 387-397. [CrossRef] 
78. Anandhi, A.; Frei, A.; Pierson, D.C.; Schneiderman, E.M.; Zion, M.S.; Lounsbury, D.; Matonse, A.H. Examination of change factor methodologies for climate change impact assessment. Water Resour. Res. 2011, 47. [CrossRef]

79. Bokke, A.S.; Taye, M.T.; Willems, P.; Siyoum, S.A. Validation of General Climate Models (GCMs) over Upper Blue Nile River Basin, Ethiopia. Atmos. Clim. Sci 2017, 7, 65-75. [CrossRef]

80. Fang, G.; Yang, J.; Chen, Y.; Zammit, C. Comparing bias correction methods in downscaling meteorological variables for a hydrologic impact study in an arid area in China. Hydrol. Earth Syst. Sci. 2015, 19, 2547-2559. [CrossRef]

81. Ta, Z.; Yu, Y.; Sun, L.; Chen, X.; Mu, G.; Yu, R. Assessment of Precipitation Simulations in Central Asia by CMIP5 Climate Models. Water 2018, 10, 1516. [CrossRef]

82. Schiemann, R.; Luthi, D.; Vidale, L.P.; Schar, C. The precipitation climate of Central Asia-Intercomparison of observational and numerical data sources in a remote semiarid region. Int. J. Climatol. 2008, 28, 295-314. [CrossRef]

83. Schiemann, R.; Luthi, D.; Schar, C. Seasonality and Interannual Variability of the Westerly Jet in the Tibetan Plateau Region. J. Clim. 2009, 22, 2940-2957. [CrossRef]

84. Abbaspour, K.C.; Rouholahnejad, E.; Vaghefi, S.; Srinivasan, R.; Yang, H.; Kløve, B. A continental-scale hydrology and water quality model for Europe: Calibration and uncertainty of a high-resolution large-scale SWAT model. J. Hydrol. 2015, 524, 733-752. [CrossRef]

85. Liu, Y.; Cui, G.; Li, H. Optimization and Application of Snow Melting Modules in SWAT Model for the Alpine Regions of Northern China. Water 2020, 12, 636. [CrossRef]

86. Tang, F.; Xu, H.; Xu, Z. Model calibration and uncertainty analysis for runoff in the Chao River Basin using sequential uncertainty fitting. Procedia Environ. Sci. 2012, 13, 1760-1770. [CrossRef]

87. Aalto, J.; Kämäräinen, M.; Shodmonov, M.; Rajabov, N.; Venäläinen, A. Features of Tajikistan's past and future climate. Int. J. Climatol. 2017, 37, 4949-4961. [CrossRef]

88. Williams, M.; Konovalov, V. Central Asia Temperature and Precipitation Data, 1879-2003; USA National Snow and Ice Data Center: Boulder, CO, USA, 2008.

89. World Bank. Key Issues for Consideration on the Proposed Rogun Hydropower Project. Available online: http://www.worldbank.org/content/dam/Worldbank/Event/ECA/central-asia/ (accessed on 27 May 2018).

90. Hill, A.F.; Minbaeva, C.K.; Wilson, A.M.; Satylkanov, R. Hydrologic Controls and Water Vulnerabilities in the Naryn River Basin, Kyrgyzstan: A Socio-Hydro Case Study of Water Stressors in Central Asia. Water 2017, 9 , 325. [CrossRef]

91. Su, B.; Huang, J.; Gemmer, M.; Jian, D.; Tao, H.; Jiang, T.; Zhao, C. Statistical downscaling of CMIP5 multi-model ensemble for projected changes of climate in the Indus River Basin. Atmos. Res. 2016, 178, 138-149. [CrossRef]

92. Xue, L.; Zhu, B.; Yang, C.; Wei, G.; Meng, X.; Long, A.; Yang, G. Study on the characteristics of future precipitation in response to external changes over arid and humid basins. Sci. Rep. 2017, 7, 15148. [CrossRef]

93. Omani, N.; Srinivasan, R.; Karthikeyan, R.; Smith, P.K. Hydrological Modeling of Highly Glacierized Basins (Andes, Alps, and Central Asia). Water 2017, 9, 111. [CrossRef]

94. Folini, D.; Wild, M. The effect of aerosols and sea surface temperature on China's climate in the late twentieth century from ensembles of global climate simulations. J. Geophys. Res. Atmos. 2015, 120, 2261-2279. [CrossRef]

95. Pendergrass, A.G.; Knutti, R.; Lehner, F.; Deser, C.; Sanderson, B.M. Precipitation variability increases in a warmer climate. Sci. Rep. 2017, 7, 17966. [CrossRef] [PubMed]

96. Wang, C. Impact of anthropogenic absorbing aerosols on clouds and precipitation: A review of recent progresses. Atmos. Res. 2013, 122, 237-249. [CrossRef]

97. Anjum, M.N.; Ding, Y.; Shangguan, D.; Liu, J.; Ahmad, I.; Ijaz, M.W.; Khan, M.I. Quantification of spatial temporal variability of snow cover and hydro-climatic variables based on multi-source remote sensing data in the Swat watershed, Hindukush Mountains, Pakistan. Meteorol. Atmos. Phys. 2019, 131, 467-486. [CrossRef]

98. Liu, J.; Luo, M.; Liu, T.; Bao, A.; De Maeyer, P.; Feng, X.; Chen, X. Local climate change and the impacts on hydrological processes in an arid alpine catchment in Karakoram. Water 2017, 9, 344. [CrossRef] 
99. Siegfried, T.; Bernauer, T.; Guiennet, R.; Sellars, S.; Robertson, A.W.; Mankin, J.; Bauer-Gottwein, P.; Yakovlev, A. Will climate change exacerbate water stress in Central Asia? Clim. Chang. 2012, 112, 881-899. [CrossRef]

100. Sorg, A.; Bolch, T.; Stoffel, M.; Solomina, O.; Beniston, M. Climate change impacts on glaciers and runoff in Tien Shan (Central Asia). Nat. Clim. Chang. 2012, 2, 725. [CrossRef]

101. Olsson, O.; Gassmann, M.; Wegerich, K.; Bauer, M. Identification of the effective water availability from streamflows in the Zerafshan river basin, Central Asia. J. Hydrol. 2010, 390, 190-197. [CrossRef]

(C) 2020 by the authors. Licensee MDPI, Basel, Switzerland. This article is an open access article distributed under the terms and conditions of the Creative Commons Attribution (CC BY) license (http://creativecommons.org/licenses/by/4.0/). 